\title{
A Synthetic DNA-Binding Domain Guides Distinct Chromatin- Modifying Small Molecules to Activate an Identical Gene Network
}

\section{$\operatorname{AUTHOR}(\mathrm{S})$ :}

Han, Le; Pandian, Ganesh N.; Chandran, Anandhakumar; Sato, Shinsuke; Taniguchi, Junichi; Kashiwazaki, Gengo; Sawatani, Yoshito; ... Xu, Yufang; Qian, Xuhong; Sugiyama, Hiroshi

\section{CITATION:}

Han, Le ...[et al]. A Synthetic DNA-Binding Domain Guides Distinct Chromatin-Modifying Small Molecules to Activate an Identical Gene Network. Angewandte Chemie International Edition 2015, 54(30): 8700-8703

\section{ISSUE DATE:}

2015-07-20

\section{URL:}

http://hdl.handle.net/2433/230861

\section{RIGHT:}

This is the accepted version of the following article: [Angewandte Chemie International Edition, (2015) 54, 30, 87008703], which has been published in final form at https://doi.org/10.1002/anie.201503607. This article may be used for non-commercial purposes in accordance with Wiley Terms and Conditions for Self-Archiving.; The full-text file will be made open to the public on 15 July 2016 in accordance with publisher's 'Terms and Conditions for Self-Archiving'.; $こ の$ 論文は出版社版でありません。引用の際には出版社版をご確認ご利用ください。; This is not the published version. Please cite only the published version. 


\title{
A synthetic DNA-binding domain guides distinct chromatin- modifying small molecules to activate an identical gene network
}

\author{
Le Han ${ }^{a, b \ddagger}$, Ganesh N. Pandian ${ }^{c \ddagger}$, Anandhakumar Chandran ${ }^{a}$, Shinsuke Sato ${ }^{c}$, Junichi Taniguchi ${ }^{a}$, \\ Gengo Kashiwazaki ${ }^{a}$, Yoshito Sawatani ${ }^{a}$, Kaori Hashiya ${ }^{a}$, Toshikazu Bando ${ }^{a}$, Yufang $\mathrm{Xu}^{\mathrm{b}}$, Xuhong \\ Qian $^{\mathrm{b}}$, and Hiroshi Sugiyama ${ }^{\mathrm{a}, \mathrm{c}}$
}

\begin{abstract}
Synthetic dual-functional ligands targeting specific DNA sequences and histone-modifying enzymes could achieve regulatory control over multi-gene networks in living cells. Unlike the broad array of targeting small molecules for histone deacetylases (HDACs) a few modulators are known for histone acetyltransferases (HATs) playing a central role in transcriptional control. As a novel chemical approach to induce selective HAT-regulated genes, we conjugated a DNA-binding domain (DBD) $\%$ with $\mathrm{N}$-(4-chloro-3-trifluoromethylphenyl)-2-ethoxy-benzamide (CTB), an artificial HAT activator. Using in vitro enzyme activity assays and microarray studies, here we demonstrate that the distinct functional small molecules could be transformed to have identical bioactivity when conjugated with a targeting DBD. This proof-of-concept synthetic strategy validates the switchable functions of HDAC and HAT in gene regulation and provides a molecular basis for developing versatile bioactive ligands.
\end{abstract}

Acetylation of histones is the critical event in transcriptional regulation and gets maintained in an equilibrium state by histone acetyltransferases (HATs) and histone deacetylases (HDACs). ${ }^{1}$ Small molecules inhibitors for HDACs can induce global changes in the acetylation profile but in a sequence-independent manner. $^{2}$ We previously synthesized a class of sequencespecific small molecules called SAHA-PIPs comprising the HDAC inhibitor suberoylanilide hydroxamic acid (SAHA) and selective DNA-binding pyrrole-imidazole polyamide (PIP)(s). The biological evaluation showed that SAHA-PIP could induce particular gene networks in mouse and human somatic cells. ${ }^{3-6}$ We showed site-specific inhibition of HDACs and subsequent acetylation of histones as the mechanism behind the distinctive gene-activating ability of SAHA-PIP. ${ }^{7}$ Transcriptionally permissive marks are acquired more reliably by activating the epigenetic writers like HATs than by blocking the erasers. ${ }^{8}$ The CREB-binding protein (CBP)/p300 family are global transcriptional co-activating HATs that act as the master regulators of gene expression and play essential roles in cell cycle control, differentiation, and apoptosis. ${ }^{9,10}$ Several small molecules are known as acetylation inhibitors. ${ }^{11}$ In contrast, only a few HAT activators like Pentadecylidenemalonate, $\mathrm{N}$ - (4-

[a] L. $\operatorname{Han}^{\mp}$, A. Chandran, J. Taniguchi, Dr. G. Kashiwazaki, Y. Sawatani, K. Hashiya, Dr. T. Bando, Prof. H. Sugiyama Department of Chemistry, Graduate School of Science, Kyoto University Kitashirakawa-Oiwakecho, Sakyo-ku, Kyoto 606-8502 E-mail:hs@kuchem.kyoto-u.ac.jp

[b] L. Han ${ }^{\ddagger}$, Prof. Y. Xu, Prof. X. Qian Shanghai Key Laboratory of Chemical Biology State Key Laboratory of Bioreactor Engineering, School of Pharmacy, East China University of Science and Technology Meilong Road 130, Shanghai, 200237 (China)

[c] Dr. G. N. Pandian ${ }^{\ddagger}$, S. Sato, Prof. H. Sugiyama Institute for Integrated Cell-Material Sciences (WPI-iCeMS) Kyoto University, Yoshida-Ushinomiyacho, Sakyo-ku, Kyoto 6068501 (Japan)

${ }^{\ddagger}$ These authors contributed equally to this work. chloro-3-trifluoromethyl-phenyl)-2-ethoxy-benzamide Nemorosone, and TTK21 are known. ${ }^{12}$

Considering the essential role of HAT in gene regulation, we chose to confer selectivity to the cell permeable HAT activator CTB by conjugating it with PIP. Recently, SAHA-PIP ' $I$ ' or SAHA-I (Figure 1) was shown to target OCT-3/4 and turn on the HDAC1-repressed core pluripotency genes. ${ }^{7}$ The HATs p300/CBP-interacting protein are known to be the critical components of the pluripotency gene network. ${ }^{13}$ As an innovative approach to induce HAT-regulated genes, we conjugated the same predesigned DNA sequences in " 1 " with CTB to synthesize CTB-PIP-I or CTB-I. $\mathrm{NH}_{2}$-CTB or CTB was synthesized by following previously published procedures (Scheme S1). ${ }^{10}$ However, $\mathrm{NH}_{2}$-CTB was not suitable for the solid-phase synthesis as the coupling monomer required carboxylic acid. For this reason, $\mathrm{HO}_{2} \mathrm{C}$-CTB that can be synthesized by coupling CTB and adipic acid, was devised to optimize the synthesis of CTB-PIP conjugates (Scheme 1) and their purification (Figure S1). Cytotoxicity studies showed that unlike SAHA that kills $50 \%$ of cells at $1 \mu \mathrm{M}$ concentration, CTB and CTB-I had no effect on HDF cells even at $5 \mu \mathrm{M}$ (Figure S2).

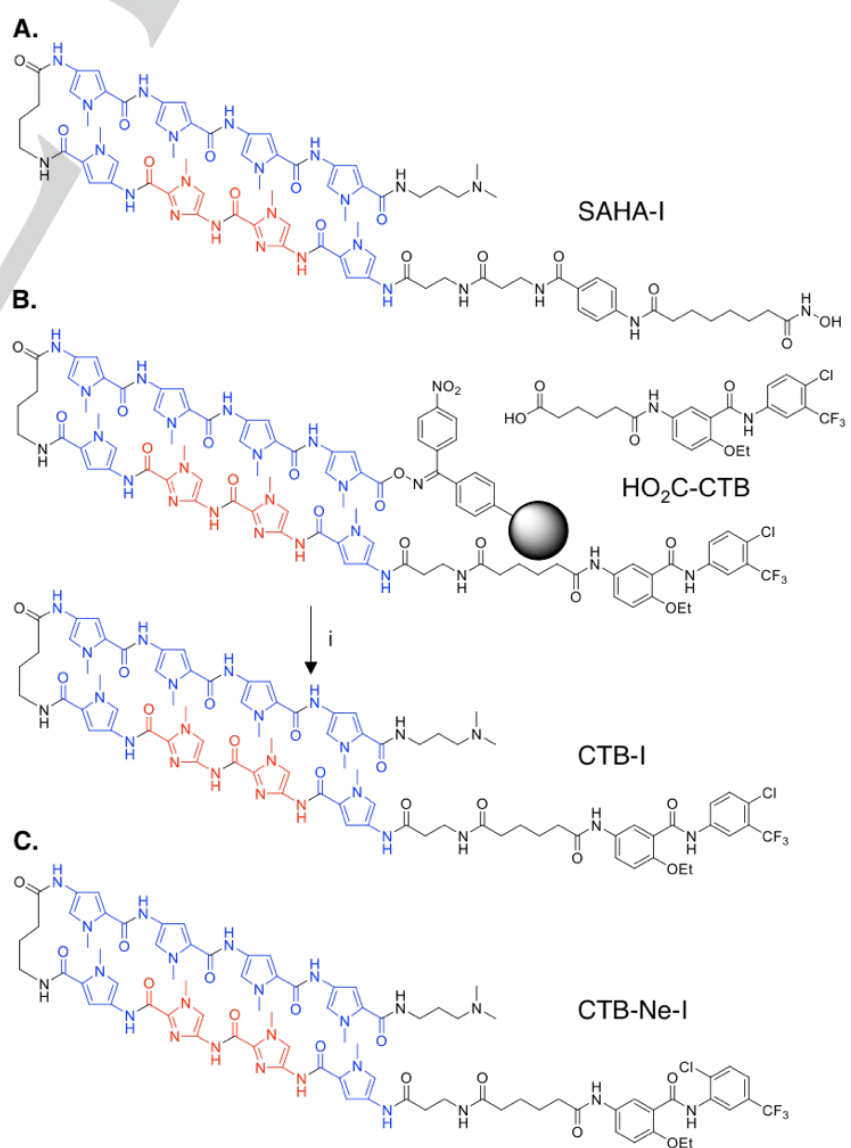

Scheme 1. (A). Structure of SAHA-I, (B) Synthetic Scheme for CTB-I. General conditions: (i) 3-dimethylaminopropylamine (Dp), $45^{\circ} \mathrm{C}, 3 \mathrm{~h}$ and (C) Structure of CTB analogue conjugate (CTB-Ne-I). 
Biological evaluation of the CTB-I was done using microarray with appropriate controls (CTB, SAHA, and SAHA-I) in the conditions optimized ${ }^{7}$ and according to preliminary studies. CTBI remarkably activated an identical cluster of genes like SAHA-I in HDFs (Figure 1A, CTB-I, and SAHA-I). CTB activated about 12 genes, and SAHA activated a different set of 17 genes (Figure $1 \mathrm{~A}$ and B, CTB and SAHA). CTB-I and SAHA-I activated about 26 and 40 genes, respectively, including 24 common genes (Figure 1B, CTB-I, and SAHA-I). Interestingly, neither CTB nor SAHA shared any genes with each other or with CTB-I and SAHA-I. The scatter plot of the upregulated transcripts in CTB-I-treated HDFs ( $>2$-fold; $p<0.05$ ) produced a strong linear correlation $\left(\mathrm{R}^{2}=0.95\right)$ with SAHA-I (Figure $\left.1 \mathrm{C}\right)$ than that with CTB-treated HDFs $\left(R^{2}=0.37\right)$ (Figure $\left.1 D\right)$.
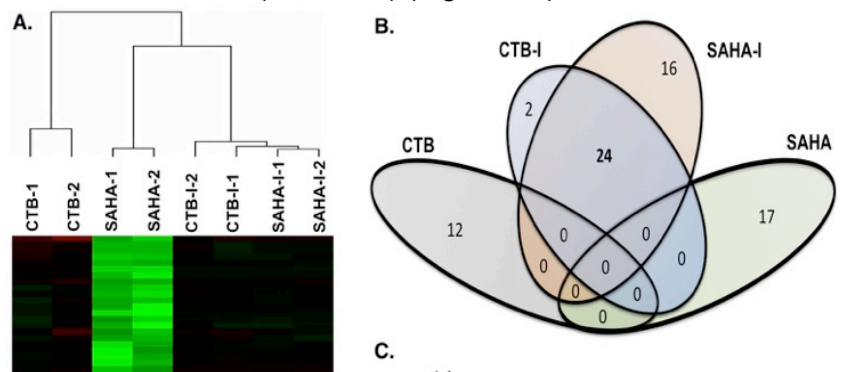

c.

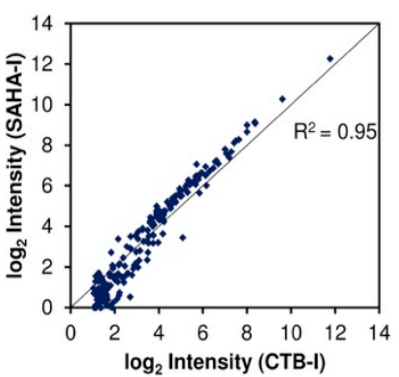

D.

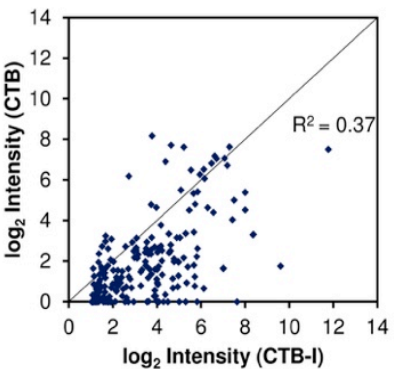

$\log _{2}$ Intensity (CTB-I)

\section{$\log _{2}$ ratio(vs DMSO)}

Figure 1. (A) A heat map based on the unsupervised hierarchical clustering analysis of the expression data derived from 4 wells for the top 138 genes in DMSO-, CTB-, SAHA-I-, and CTB-I-treated HDFs (>10-fold and $p<0.05)$. (B) A four-circle Venn diagram from the data $(>5$-fold and $p<0.05)$ showed that the number of genes upregulated in effector treated HDFs. (C) Scatter plot of the data $(>2$-fold and $p<0.05)$ show a high correlation $\left(R^{2}=0.95\right)$ between replicate samples of CTB-I and SAHA-I treated HDFs to suggest similar targets. (D) Conversely, a plot of CTB-1-treated HDFs vs. CTB-treated HDFs showed a relatively weak correlation $\left(R^{2}=0.37\right)$ to suggest distinct bioactivity.

CTB-I favored transcriptional activation over repression because 48 genes got upregulated, and 19 genes were downregulated (Table S1). Thus, conjugation of PIP markedly altered and boosted the bioactivity of both CTB and SAHA by 2fold and directed them to identical gene network(s). Analysis of the upstream effectors showed that both SAHA-I and CTB-I activated $O C T-3 / 4$ regulated pluripotency genes (Figure $2 \mathrm{~A}$ ). QRT-PCR analysis validated the expression of the genes identified in Figure $2 \mathrm{~A}$, and the endogenous expression of OCT $3 / 4$ was significantly $(P<0.05)$ induced by more than 50 -fold in both SAHA-I and CTB-I treated HDFs. CTB-I also significantly $(P<0.05)$ induced SOX2, NANOG, LIN28B, EPCAM, and SALL4 and markedly upregulated ZIC3 and DPPA4 (Figure 2B-I). This report is the first to show that directed HAT activity trigger the

activation of key pluripotency genes and microRNAs like MIR302C ${ }^{14}$ (Figure S3).

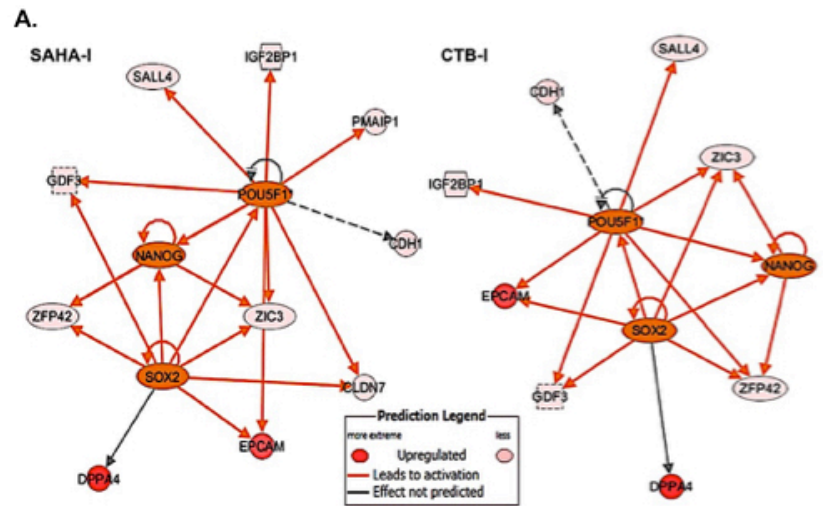

B.

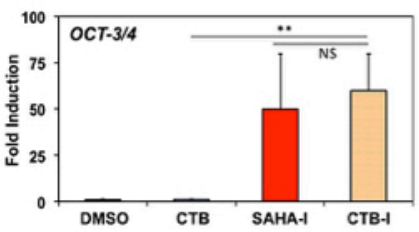

D.

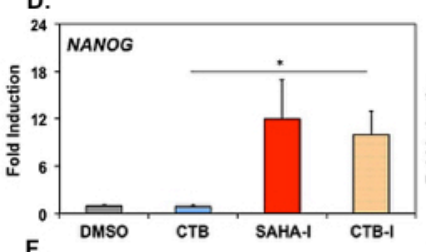

F.

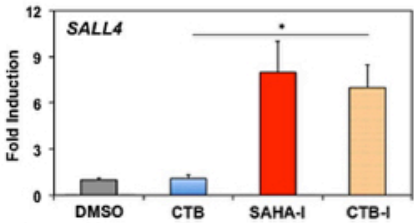

H.

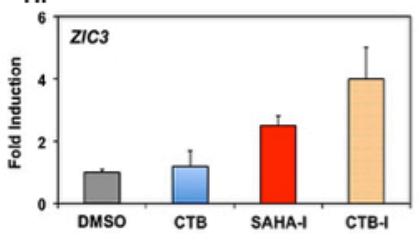

J. $\quad$ Chr 6: 31,135kb-31,141kb

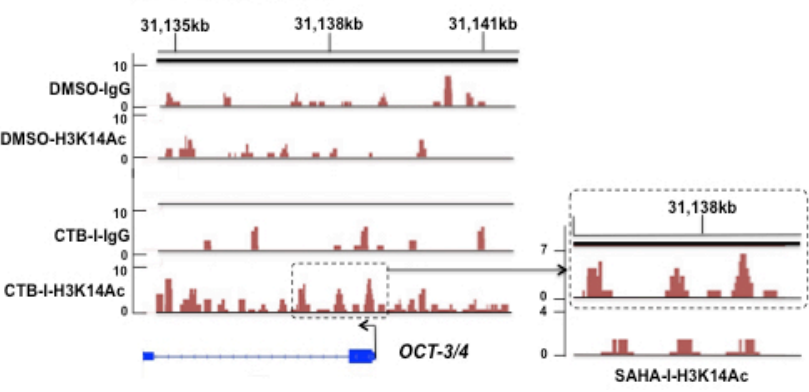

Figure 2. (A) Analysis of the upstream regulators from the summary of data obtained from 4 wells show that like SAHA-I ${ }^{7}$, CTB-I activate the OCT-3/4 pathway. QRT-PCR analysis of (B) OCT-3/4, (C) SOX2, (D) NANOG, (E) LIN28B, (F) SALL4, (G) EPCAM, (H) ZIC3 and (I) DPPA4 in the effectors (CTB, CTB-I and SAHA-I) treated HDFs. Mean \pm SD from 18 wells, $p<0.05$ (6 biological replicates). (J) ChIP-seq analysis after immunoprecipitation with $\mathrm{H} 3 \mathrm{~K} 14 \mathrm{ac}$ antibody show hyperacetylation in the promoter and transcribed regions of $O C T-3 / 4$ like SAHA-I ${ }^{7}$ (Enlarged and indicated).

CTB-I and SAHA-I displayed similar gene expression profiles and suggested a common mechanism. To clarify the mode of action, we synthesized a CTB analogue conjugate termed CTB$\mathrm{Ne}-\mathrm{I}$ where the relative position of $-\mathrm{CF}_{3}$ and $-\mathrm{Cl}$ in CTB is 
changed to lack HAT activity according to Kundu and coworkers. ${ }^{10}$ (Scheme S1c). A HAT activity study in HDF cells showed that CTB-I retained the HAT activity of CTB as HAT activity got significantly increased in CTB and CTB-I-treated HDFs when compared to that treated with an inactive CTB-Ne-I (Figure S4). SAHA-I showed only a mild increase in HAT activity to suggest the indirect effect caused by HDAC inhibition. This pattern was further substantiated through the enzymatic activity assay study carried out in HeLa nuclear extract where only CTB and CTB-I significantly increased HAT activity when compared to SAHA-I and CTB-Ne-I (Figure S5). Unlike CTB-I and SAHA-I, the inactive analogue CTB-Ne-I did not upregulate the pluripotency genes to validate the need for CTB-mediated HAT activity in gene induction (Figure S6). An HDAC activity assay in cells treated with individual effectors precluded HDAC inhibitory activity of CTB as the possible gene induction mechanism as only SAHA and SAHA-I resulted in HDAC inhibition in cells (Figure S7). In vitro assay carried out with the nuclear extracts from HeLa cells and HDFs further validated this pattern (Figure S8). Chromatin immunoprecipitation (ChIP)-seq analysis revealed hyperacetylation in the transcribed regions of OCT $-3 / 4$ in CTB-I-treated HDFs than in DMSO-treated HDFs (Figure 2J). Interestingly, like SAHA-I, CTB-I also resulted in the enrichment in the acetylation level of H3K14 (Figure S9). Also, peaks around the putative promoter region having ' $\mathrm{l}$ ' binding site were identical in CTB-I and SAHA-I-treated HDFs (Figure 2J (box)).

Recently, high-throughput sequencing studies substantiated the strong binding affinity of PIP ${ }^{15}$, and in accordance with gene expression pattern; SAHA-I had superior binding specificity toward the promoter sequence of human OCT $-3 / 4^{7}$ than the germ cell gene PIWIL $1^{5}$. The in vitro binding association and ChIP-PCR studies verified that the pattern observed in the model oligonucleotide duplex can be extrapolated to the corresponding sequence within the chromatin. ${ }^{7}$ CTB-I also triggered hyperacetylation marks in NANOG, SOX2, DPPA4, EPCAM, LIN28, and ZIC3 (Figure S10), however, none had the notable acetylation profile observed in the promoter and transcribed regions of OCT-3/4. CTB-I did not show a marked difference in the acetylation pattern observed in the germ cell genes (PIWIL1 and TDRD1) and the housekeeping gene (GAPDH and HMGB1)(Figure S11). The top five significantly enriched pathways verified the CTB-I effect on the expression of the key pluripotency genes (Table S2, CTB-I treated HDFs). CTB induced an entirely different set of genes associated with liver X receptor (LXR) (Table S2, CTB treated HDFs). HDAC1 and p300 bind directly to the overlapping regions of the histone $\mathrm{H} 3$ tail and compete with each other. ${ }^{16}$ HDAC1 is known to regulate the pluripotency and lineage-specific transcriptional network. ${ }^{17}$ The combination of CTB-I and SAHA-I resulted in the expression of OCT-3/4, which has a similar expression profile attained with their individual treatment (Figure S12). Because p300 can acetylate HDAC1 upon activation and attenuate its deacetylase activity, these two synthetic histone-modifiers could be inducing a similar pattern of gene expression. Although the actual mechanism underlying the identical bioactivity is not straightforward, site-specific acetylation triggered by SAHAmediated HDAC inhibition or CTB-mediated HAT activation at a particular key sequence could be causing the activation of OCT$3 / 4$ and its regulated genes.

Considering the importance of HATs in the multi-gene network associated cell biological processes, our study could open new opportunities to modulate HAT-regulated gene(s). CTB-I displayed similar HAT activity pattern in HeLa cells as HDFs to suggest the potential of this strategy in p300 deficient cells. Since the achievement of chemically induced pluripotent stem cells ${ }^{18}$, bioactive ligands aiding cellular reprogramming are in rising demand. Our synthetic strategy could be harnessed to probe the functional interplay between the histone-modifying enzymes in co-ordinating the therapeutically important genes. Tuning of the functional module ${ }^{19}$ and expansion of the recognition ability ${ }^{20}$ could lead to the construction of robust epigenetic switches with versatile bioactivity.

\section{Experimental Section}

Experimental details are shown in the supporting information.

\section{Author Contributions}

\$These authors contributed equally to this work. Experiments were designed by H.S., G.N.P. and T.B. L.H., G.N.P., A.C., K.H., and S.S. performed research. G.N.P., L.H., J.T., A.C., S.S. and G.K. analysed the data. The manuscript was written by L.H., H.S., G.N.P. and G.K. Y.X and X.Q reviewed the manuscript.

\section{Acknowledgements}

This work was supported by JSPS KAKENHI (24225005), "Basic Science and Platform Technology Program for Innovative Biological Medicine" and "JSPS-NSF International Collaborations in Chemistry (ICC)" to HS and Grant No. 24310155 to TB. We also thank challenging exploratory research grant for support to G.N.P. China Scholarship Council (CSC) support L. H.

\section{Keywords: DNA recognition $\cdot$ genetic switches $\cdot$ histone} acetyltransferase $\cdot$ polymerase chain reaction $\cdot$ synthetic biology

[1] V. V. Ogryzko, R. L. Schiltz, V. Russanova, B. H. Howard, Y. Nakatani, Cell, 1996, 87, 953-959.

[2] H. Sugiyama. G. N. Pandian, Pharmaceuticals 2012, 6, 1-24.

[3] G. N. Pandian, Y. Nakano, S. Sato, H. Morinaga, T. Bando, H. Nagase, H. Sugiyama, Sci. Rep. 2012, 2, e544.

[4] G. N. Pandian, J. Taniguchi, S. Junetha, S. Sato, L. Han, A. Saha, C Anandhakumar, T. Bando, H. Nagase, T. Vaijayanthi, R. D. Taylor, H. Sugiyama, Sci. Rep. 2014, 4, e3843.

[5] L. Han, G. N. Pandian, S. Junetha, S. Sato, C. Anandhakumar, J. Taniguchi, A. Saha, T. Bando, H. Nagase, H. Sugiyama, Angew. Chem. Int. Ed. 2013, 52, 13410-13413.

[6] G. N. Pandian, R. D. Taylor, S. Junetha, A. Saha, C. Anandhakumar, T. Vaijayanthi, H. Sugiyama, Biomater. Sci. 2014, 2, 1043-1056.

[7] G. N. Pandian, S. Sato, C. Anandhakumar, J. Taniguchi, K. Takashima, J. Syed, L. Han, A. Saha, T. Bando, H. Nagase, H. Sugiyama, ACS Chem. Biol. 2014, 9, 2729-2736.

[8] H. M. Chan, N. B. L. Thangue, J. Cell Sci. 2001, 114, 2363-2373. [9] B. R. Selvi, J.-C. Cassel, T. K. Kundu, A.-L. Boutillier, BBA-Gene Regul. Mech. 2010, 1799, 840-853.

[10] K. Mantelingu, A. H. Kishore, K. Balasubramanyam, G. V. P. Kumar, M. Altaf, S. N. Swamy, R. Selvi, C. Das, C. Narayana, K. S. Rangappa, T. K. Kundu, J. Phys. Chem. B 2007, 111, 4527-4534.

[11] K. Balasubramanyam, R. A. Varier, M. Altaf, V. Swaminathan, N. B. Siddappa, U. Ranga, T. K. Kundu, J. Biol. Chem. 2004, 279, 51163-51171. [12] a) G. Sbardella, S. Castellano, C. Vicidomini, D. Rotili, A. Nebbioso, M. Miceli, L. Altucci, A. Mai, Bioorg. Med. Chem. Lett. 2008, 18, 2788-2792; b) S. Chatterjee, P. Mizar, R. Cassel, R. Neidl, B. R. Selvi, D. V. Mohankrishna, B. M. Vedamurthy, A. Schneider, O. Bousiges, C. Mathis, J.-C. Cassel, M. Eswaramoorthy, T. K. Kundu, A.-L. Boutillier, J. Neurosci. 2013, 33, 10698 10712; c) F. Dal Piaz, A. Tosco, D. Eletto, A. L. Piccinelli, O. Moltedo, S. Franceschelli, G. Sbardella, P. Remondelli, L. Rastrelli, L. Vesci, C. Pisano, N. De Tommasi, Chembiochem 2010, 11, 818-827; d) K. Balasubramanyam, V. Swaminathan, A. Ranganathan, T. K. Kundu, J. Biol. Chem. 2003, 278, 19134-19140; e) K. Balasubramanyam, M. Altaf, R. A. Varier, V. Swaminathan, A. Ravindran, P. P. Sadhale, T. K. Kundu, J. Biol. Chem. 2004, 279, 3371633726.

[13] J. M. Chitilian, G. Thillainadesan, J. L. Manias, W. Y. Chang, E. Walker M. Isovic, W. L. Stanford, J. Torchia, Stem Cells 2014, 32, 204-215.

[14] S. L. Lin, D. C. Chang, S. Chang-Lin, C. H. Lin, D. T. Wu, D. T. Chen, S. Y. Ying, RNA 2008, 14, 2115-2124.

[15] C. Anandhakumar, Y. Li, S. Kizaki, G. N. Pandian, K. Hashiya, T. Bando, H. Sugiyama, ChemBioChem 2014, 15, 2647-2651.

[16] X. Li, H. Yang, S. Huang, Y. Qu, PLoS ONE 2014, 9, e94523.

[17] B. L. Kidder, S. Palmer, Nucleic Acids Res. 2012, 40, 2925-2939.

[18] a) P. Hou, Y. Li, X. Zhang, C. Liu, J. Guan, H. Li, T. Zhao, J. Ye, W. Yang, K. Liu, J. Ge, J. Xu, Q. Zhang, Y. Zhao, H. Deng, Science 2013, 341, 651-654; b) Y.-L. Wu, Ganesh N. Pandian, Y.-P. Ding, W. Zhang, Y. Tanaka, H. Sugiyama, Chem. Biol. 2013, 20, 1311-1322; c) S. Masuda, J. Wu, T. Hishida, G. N. Pandian, H. Sugiyama, J. C. Izpisua Belmonte, J. Mol. Cell Biol. 2013, 5, 354-355

[19] A. Saha, G. N. Pandian, S. Sato, J. Taniguchi, K. Hashiya, T. Bando, H. Sugiyama, Bioorg. Med. Chem. 2013, 21, 4201-4209.

[20] J. W. Trauger, E. E. Baird, P. B. Dervan, J. Am. Chem. Soc. 1998, 120, 3534-3535. 


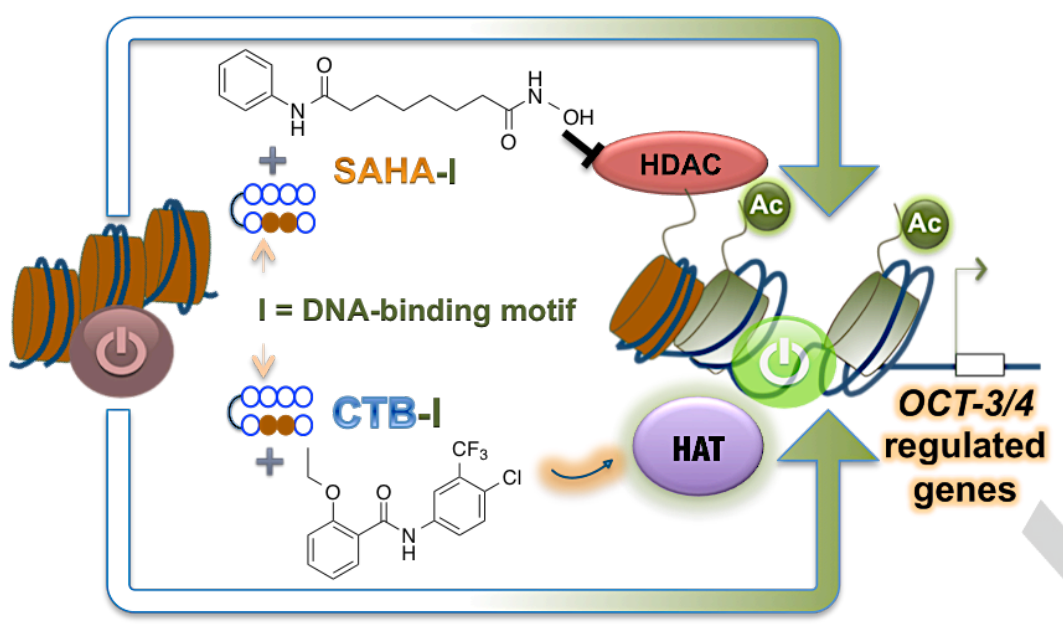

Le Han, Ganesh N. Pandian,

Anandhakumar Chandran, Shinsuke

Sato, Junichi Taniguchi, Gengo

Kashiwazaki, Kaori Hashiya, Toshikazu

Bando, Yufang Xu, Xuhong Qian, and

Hiroshi Sugiyama*

Page No. - Page No.

A synthetic DNA-binding domain guides distinct chromatin-modifying small molecules to activate an identical gene network

Distinct to Identical - A Chemical Transformation. A novel conjugation of selective DNA-binding 'I' with $\mathrm{N}$-(4-chloro-3-trifluoromethyl-phenyl)-2-ethoxy-benzamide (CTB), a histone acetyltransferase (HAT) activator yielded an epigenetic switch with bioactivity identical to the distinct operative histone deacetylase (HDAC) inhibiting SAHA-I. 


\section{Table of contents}

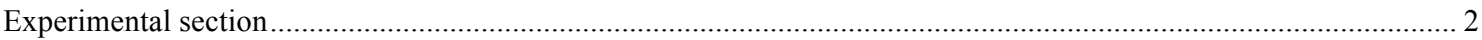

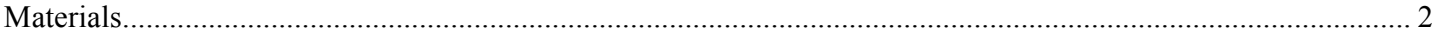

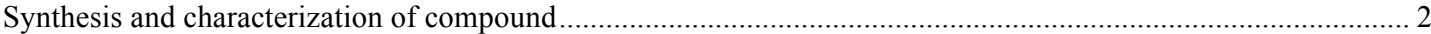

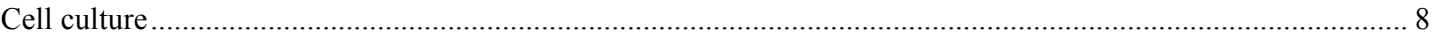

Microarray analysis and Quantification of gene expression ........................................................................... 8

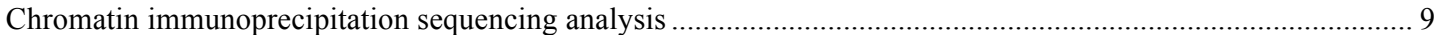

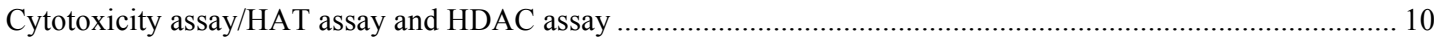

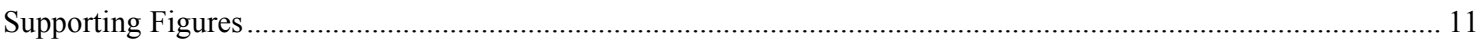

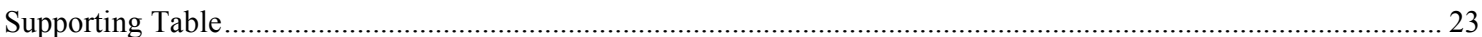

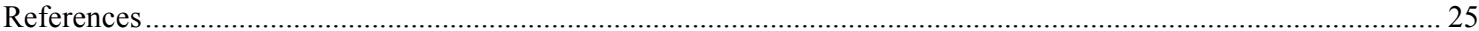


General: All chemical reagents and solvents were obtained from commercial sources and used without further purification. ${ }^{1} \mathrm{H}$ NMR were recorded on a JEOL JNM ECA-600 spectrometer with chemical shifts expressed as ppm $\left(\mathrm{Me}_{4} \mathrm{Si}\right.$ as $\left.0 \mathrm{ppm}\right)$. The purities were analyzed on JASCO Engineering PU-2089 plus series system with detection at $254 \mathrm{~nm}$, equipping a Shimadzu LC-10AD liquid chromatograph pump, an SPD-10A UV/vis detector, and a Chemcobond 5-ODS-H reversed-phase column $(4.6 \times 150 \mathrm{~mm})$. A gradient of $0-100 \%$ acetonitrile and $0.1 \%$ TFA in water at a flow rate of $1.0 \mathrm{~mL} / \mathrm{min}$ over $40 \mathrm{~min}$ was used as eluent. HPLC purification was performed with a JASCO CCPS HPLC pump, a JASCO UV8020 HPLC UV/vis detector, and a Chemcobond 5-ODS-H reversed-phase column $(10 \times 150 \mathrm{~mm})$ in $0.1 \% \mathrm{TFA}$ in water with $\mathrm{CH}_{3} \mathrm{CN}$ as eluent at a flow rate of $1.0 \mathrm{~mL} / \mathrm{min}$, and a linear gradient elution of $\mathrm{CH}_{3} \mathrm{CN}$ with detection at $254 \mathrm{~nm}$. ESI-TOFMS was produced on a BioTOF II (Bruker Daltonics) mass spectrometer using a positive ionization mode. UV spectra were measured on a Nanodrop ND-1000 spectrophotometer. The biological experiments were only employed on compounds whose purity is at least $95 \%$.

\section{Scheme S1. Synthetic Scheme for $\mathrm{NH}_{2}-\mathrm{CTB}$ and $\mathrm{CTB}^{1}$}<smiles></smiles><smiles>CC(=O)c1cc([N+](=O)[O-])ccc1O</smiles><smiles>C#CC</smiles><smiles>CC#CC</smiles><smiles>CCOc1ccc([N+](=O)[O-])cc1C(=O)O</smiles><smiles>Nc1ccc(Cl)c(C(F)(F)F)c1</smiles><smiles>CCO[N+](=O)[O-]</smiles><smiles>CCOc1ccc(C)cc1C(=O)Nc1ccc(Cl)c(C(F)(F)F)c1</smiles><smiles>CCOc1ccc(N)cc1C(=O)Nc1ccc(Cl)c(C(F)(F)F)c1</smiles><smiles>CCOc1ccccc1C(=O)O</smiles><smiles>Nc1ccc(Cl)c(C(F)(F)F)c1</smiles><smiles>CCOc1ccccc1C(=O)Nc1ccc(Cl)c(C(F)(F)F)c1</smiles>

General conditions: (i) sulfuric acid, methanol, reflux, overnight; (ii) iodoethane, $\mathrm{K}_{2} \mathrm{CO}_{3}, N, N$-dimethylformamide, 60 ${ }^{\circ} \mathrm{C}, \quad 2 \mathrm{~h}$; (iii) $\mathrm{LiOH} \cdot \mathrm{H}_{2} \mathrm{O}, \quad \mathrm{H}_{2} \mathrm{O} / \mathrm{MeOH}$, overnight at RT; (iv) $\mathrm{HCTU}, \quad N, N$-diisopylethylamine, $\mathrm{N}, \mathrm{N}$-dimethylformamide, overnight at RT; (v) $\mathrm{H}_{2}, \mathrm{Pd} / \mathrm{C}$, ethyl acetate, $6 \mathrm{~h}$ at $\mathrm{RT}$. 


\section{Synthesis of CTB unit for P-I conjugates}<smiles>CN(C)CCCNC(=O)c1cc(NC(=O)c2cc(NC(=O)c3cc(NC(=O)c4cc(NC(=O)CCCCC(=O)NCCC(=O)NCCCC(=O)O)cn4C)cn3C)cn2C)cn1C(=O)c1cc(C(=O)Nc2cn(C)c(C(=O)Nc3cc(C(=O)NCCCC(=O)Nc4cc(C(=O)Nc5cc(C(=O)Nc6cc(C(=O)NCCCC(=O)O)n(C)c6)n(C)c5)n(C)c4)n(C)n3)n2)n(C)c1</smiles>

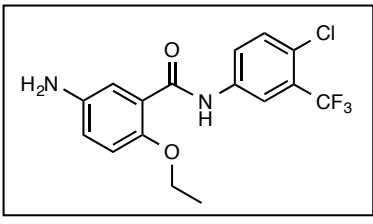

CTB unit<smiles>O=C(O)c1cc([N+](=O)[O-])ccc1O</smiles>

5-nitrosalycylic acid $\mathrm{rt}=15.1 \mathrm{~min}$

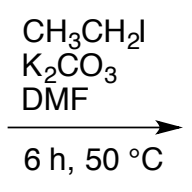

$73 \%$<smiles>CCOc1ccc([N+](=O)[O-])cc1OCC</smiles>

$\mathrm{rt}=23.5 \mathrm{~min}$
HPLC : $0-100 \% 0.1 \%$ TFA- $\mathrm{CH}_{3} \mathrm{CN}, 40 \mathrm{~min}$

To a solution of compound 5-nitrosalcylic acid (1 g, $5.46 \mathrm{mmol})$ in DMF (15 mL) were added $\mathrm{K}_{2} \mathrm{CO}_{3}(4.52 \mathrm{~g}, 32.8$ mmol) and iodoethane $(2.2 \mathrm{ml}, 27.5 \mathrm{mmol})$. The reaction mixture was stirred for $6 \mathrm{~h}$ at $50{ }^{\circ} \mathrm{C}$. Evaporation of the solvent gave a yellow residue, which was filtrated with water $(20 \mathrm{~mL})$ to produce $\mathbf{1}(955 \mathrm{mg}, 3.99 \mathrm{mmol}, 73 \%)$ as a yellow powder.

$1:{ }^{1} \mathrm{H}$ NMR $\left(600 \mathrm{MHz}, \mathrm{CDCl}_{3}\right) \delta 8.67(\mathrm{~d}, J=2.7 \mathrm{~Hz}, 1 \mathrm{H} ; \mathrm{Ar}-\mathrm{H}), 8.33(\mathrm{dd}, J=2.7,9.6 \mathrm{~Hz}, 1 \mathrm{H} ; \mathrm{Ar}-\mathrm{H}), 7.02(\mathrm{~d}, J=$ $9.6 \mathrm{~Hz}, 1 \mathrm{H} ; \mathrm{Ar}-\mathrm{H}), 4.39$ (q, J = 7.3 Hz, 2H; $\left.\mathrm{CH}_{2}\right), 4.23\left(\mathrm{q}, J=7.3 \mathrm{~Hz}, 2 \mathrm{H} ; \mathrm{CH}_{2}\right), 1.52\left(\mathrm{t}, J=7.3 \mathrm{~Hz}, 3 \mathrm{H} ; \mathrm{CH}_{3}\right), 1.41(\mathrm{t}$, $\left.J=7.3 \mathrm{~Hz}, 3 \mathrm{H} ; \mathrm{CH}_{3}\right)$
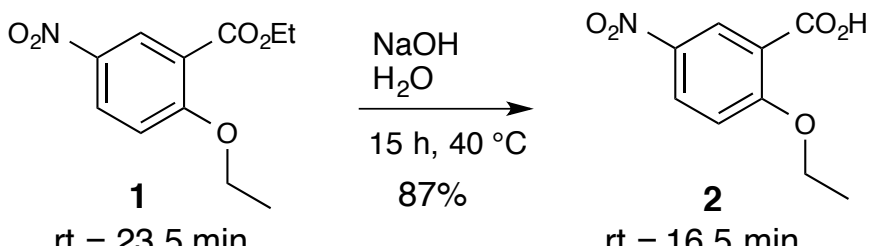

HPLC : $0-100 \% 0.1 \%$ TFA-CH ${ }_{3} \mathrm{CN}, 40 \mathrm{~min}$

To a solution of compound $1(950 \mathrm{mg}, 3.99 \mathrm{mmol})$ in water $(15 \mathrm{~mL})$ were added $\mathrm{NaOH}(1 \mathrm{~g}, 25 \mathrm{mmol})$. The reaction mixture was stirred for $15 \mathrm{~h}$ at $40{ }^{\circ} \mathrm{C}$. Atfter the filtration, quenching of the solvent by diluted $\mathrm{HCl}$ gave a white precipitation, which was filtrated with water $(10 \mathrm{~mL})$ to produce $2(733 \mathrm{mg}, 3.47 \mathrm{mmol}, 87 \%)$ as a white powder. 
$2:{ }^{1} \mathrm{H}$ NMR $\left(600 \mathrm{MHz}, \mathrm{CDCl}_{3}\right) \delta 9.06(\mathrm{~d}, J=2.8 \mathrm{~Hz}, 1 \mathrm{H} ; \mathrm{Ar}-\mathrm{H}), 8.44(\mathrm{dd}, J=2.8,8.9 \mathrm{~Hz}, 1 \mathrm{H} ; \mathrm{Ar}-\mathrm{H}), 7.16(\mathrm{~d}, J=$ $8.9 \mathrm{~Hz}, 1 \mathrm{H} ; \mathrm{Ar}-\mathrm{H}), 4.45\left(\mathrm{q}, J=6.9 \mathrm{~Hz}, 2 \mathrm{H} ; \mathrm{CH}_{2}\right), 1.64\left(\mathrm{t}, J=6.9 \mathrm{~Hz}, 3 \mathrm{H} ; \mathrm{CH}_{3}\right)$<smiles>CCOc1ccc([N+](=O)[O-])cc1C(=O)O</smiles><smiles>Nc1ccc(Cl)c(C(F)(F)F)c1</smiles>

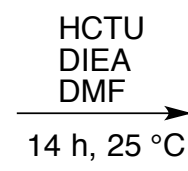<smiles>CCOc1ccc([N+](=O)[O-])cc1C(=O)Nc1ccc(Cl)c(C(F)(F)F)c1</smiles>

To a solution of compound 2 (733 mg, $3.47 \mathrm{mmol})$ in DMF (11 mL) were added HCTU (1.58 g, $3.82 \mathrm{mmol})$, diisopropyl amine $(0.73 \mathrm{~mL}, 4.16 \mathrm{mmol})$. After the reaction solution was stirred for $10 \mathrm{~min}$, 5-amino-2-chlorobenzotrifluoride $(680 \mathrm{mg}, 3.47 \mathrm{mmol})$ were added. The reaction mixture was stirred for $14 \mathrm{~h}$ at $25^{\circ} \mathrm{C}$. Evaporation of the solvent gave a yellow residue, which was filtrated with $5 \% \mathrm{HCl}(20 \mathrm{~mL})$, water $(20 \mathrm{~mL})$ to produce crude 3 (1.85 g, containing HCTU residue) as a brown powder.

ESI-TOF-MS (positive) m/z calcd for $\mathrm{C}_{16} \mathrm{H}_{13} \mathrm{ClF}_{3} \mathrm{~N}_{2} \mathrm{O}_{4}{ }^{+}[M+\mathrm{H}]^{+} 389.0510$; found 389.0527.<smiles>CCOc1ccc([N+](=O)[O-])cc1C(=O)Nc1ccc(Cl)c(C(F)(F)F)c1</smiles>

$\mathrm{rt}=30.7 \mathrm{~min}$

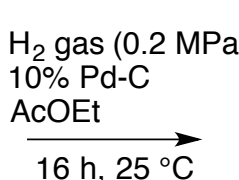

$16 \mathrm{~h}, 25^{\circ} \mathrm{C}$<smiles>CCOc1ccc(N)cc1C(=O)Nc1ccc(Cl)c(C(F)(F)F)c1</smiles>

$\mathrm{rt}=20.7 \mathrm{~min}$

To a solution of compound 3 (500 mg, containing HCTU residue) in AcOEt (10 mL) were added 10\% Pd-C (20 $\mathrm{mg})$. The reaction mixture was stirred for $16 \mathrm{~h}$ at $\mathrm{rt}$ under $\mathrm{H}_{2}$ gas $(0.2 \mathrm{MPa})$. Atfter the celite filtration by $\mathrm{CH}_{2} \mathrm{Cl}_{2}-\mathrm{MeOH}$, Evaporation of the solvent gave a brown residue 4 (387 mg, containing HCTU residue) as a white powder. Analytical HPLC $\mathrm{t}_{\mathrm{R}}=20.8 \mathrm{~min} ;{ }^{1} \mathrm{H}$ NMR $\left(600 \mathrm{MHz}, \mathrm{CDCl}_{3}\right): \delta 10.45(\mathrm{~s}, 1 \mathrm{H}), 7.99(\mathrm{~d}, J=2.8 \mathrm{~Hz}, 1 \mathrm{H}), 7.76$ (s, 1H), $7.60(\mathrm{~d}, J=2.7 \mathrm{~Hz}, 1 \mathrm{H}), 7.47(\mathrm{~d}, J=8.3 \mathrm{~Hz}, 1 \mathrm{H}), 6.87-6.83(\mathrm{~m}, 2 \mathrm{H}), 4.21(\mathrm{q}, J=6.9 \mathrm{~Hz}, 2 \mathrm{H}), 3.62(\mathrm{br}, 2 \mathrm{H})$, $1.58(\mathrm{t}, J=6.9 \mathrm{~Hz}, 3 \mathrm{H})$. ESI-TOF-MS (positive) $\mathrm{m} / \mathrm{z}$ calcd for $\mathrm{C}_{16} \mathrm{H}_{15} \mathrm{ClF}_{3} \mathrm{~N}_{2} \mathrm{O}_{2}{ }^{+}[M+\mathrm{H}]^{+}$359.0769; found 359.0774. 

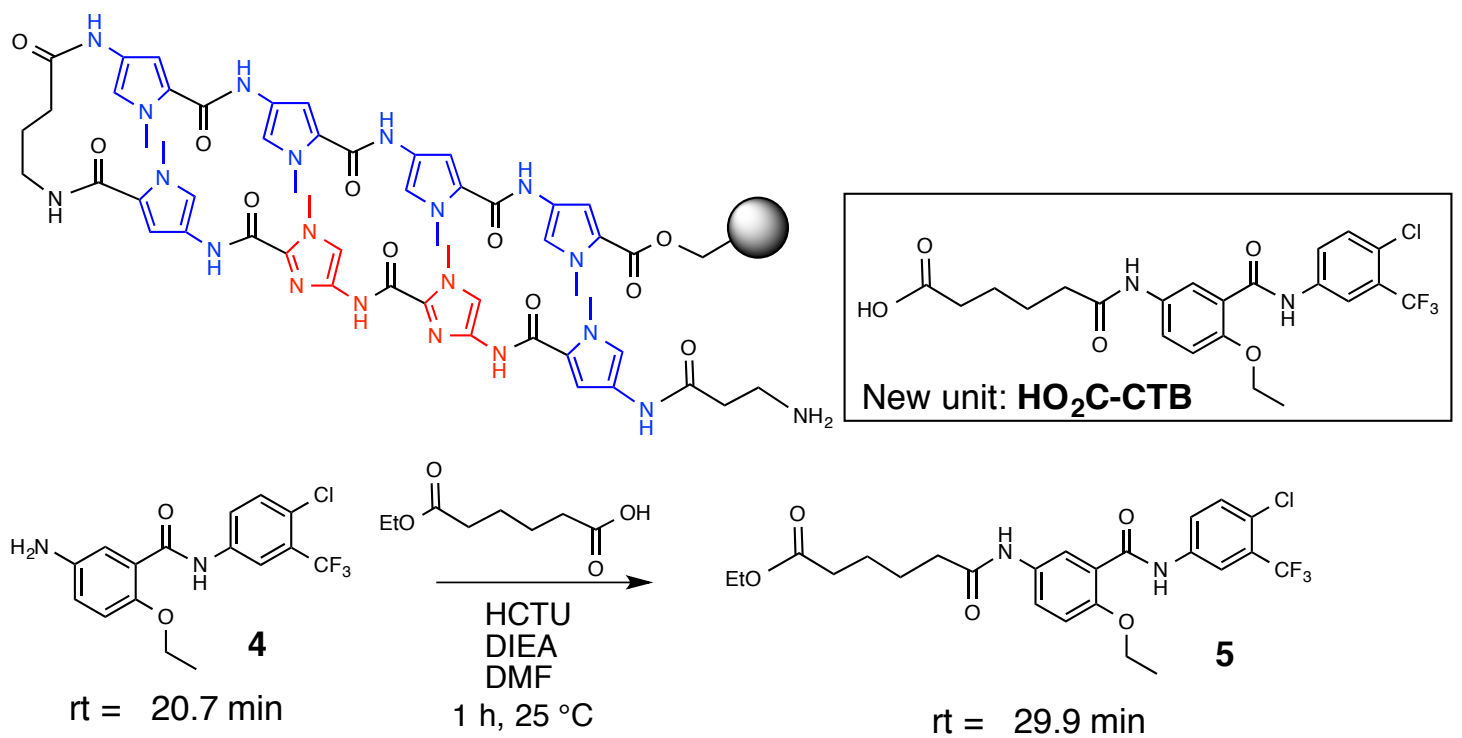

To a solution of compound 4 (660 mg, containing HCTU residue) in DMF (7 mL) were added HCTU (820 mg, 1.98 mmol), diisopropyl amine $(0.41 \mathrm{~mL}, 2.38 \mathrm{mmol})$. The reaction mixture was stirred for $1 \mathrm{~h}$ at $25{ }^{\circ} \mathrm{C}$. Evaporation of the solvent gave a brown residue, which was filtrated with $1 \mathrm{~N} \mathrm{NaOH}(20 \mathrm{~mL})$ for the removal of $\mathrm{HCTU}$ residue, to produce crude 5 (580 $\mathrm{mg}, 1.13 \mathrm{mmol})$ as a light-brown powder.

ESI-TOF-MS (positive) $\mathrm{m} / \mathrm{z}$ calcd for $\mathrm{C}_{24} \mathrm{H}_{27} \mathrm{ClF}_{3} \mathrm{~N}_{2} \mathrm{O}_{5}{ }^{+}[M+\mathrm{H}]^{+}$515.1555; found 515.1127.<smiles>CCOc1ccc(NC(=O)CCCCC(=O)O)cc1C(=O)Nc1ccc(OCC)c(C(=O)Nc2ccc(Cl)c(C(F)(F)F)c2)c1</smiles>

To a solution of compound $5(580 \mathrm{mg}, 1.13 \mathrm{mmol})$ in water $(20 \mathrm{~mL})$ and EtOH $(20 \mathrm{~mL})$ were added $\mathrm{NaOH}(1 \mathrm{~g}$, $25 \mathrm{mmol}$ ). The reaction mixture was stirred for $2 \mathrm{~h}$ at $90{ }^{\circ} \mathrm{C}$ to change brown solution. Atfter the evaporation of $\mathrm{EtOH}$, quenching of the solvent by diluted $\mathrm{HCl}$ gave a white precipitation, which was filtrated with water $(10 \mathrm{~mL})$ to produce 6 (503 $\mathrm{mg}, 1.04 \mathrm{mmol}, 92 \%)$ as a white powder.

$6:{ }^{1} \mathrm{H}$ NMR $\left(600 \mathrm{MHz}, \mathrm{d}_{6}\right.$-DMSO) $\delta 10.51(\mathrm{~s} 1 \mathrm{H} ; \mathrm{NH}), 9.92(\mathrm{~s}, 1 \mathrm{H} ; \mathrm{NH}), 8.33(\mathrm{~s}, 1 \mathrm{H} ; \mathrm{Ar}-\mathrm{H}), 7.95(\mathrm{~d}, J=8.9 \mathrm{~Hz}, 1 \mathrm{H}$; Ar-H), $7.87(\mathrm{~d}, J=2.0 \mathrm{~Hz}, 1 \mathrm{H} ; \mathrm{Ar}-\mathrm{H}), 7.72(\mathrm{~m}, 2 \mathrm{H} ; \mathrm{Ar}-\mathrm{H}$ x 2), $7.13(\mathrm{~d}, J=8.9 \mathrm{~Hz}, 1 \mathrm{H} ; \mathrm{Ar}-\mathrm{H}), 4.13(\mathrm{q}, J=6.9 \mathrm{~Hz}$, $\left.2 \mathrm{H} ; \mathrm{CH}_{2}\right), 2.29\left(\mathrm{t}, J=7.3 \mathrm{~Hz}, 2 \mathrm{H} ; \mathrm{CH}_{2}\right), 2.24\left(\mathrm{t}, J=7.3 \mathrm{~Hz}, 2 \mathrm{H} ; \mathrm{CH}_{2}\right), 1.59\left(\mathrm{~m}, 2 \mathrm{H} ; \mathrm{CH}_{2}\right), 1.52\left(\mathrm{~m}, 2 \mathrm{H} ; \mathrm{CH}_{2}\right), 1.36(t$, 
$\mathrm{J}=6.9 \mathrm{~Hz}, 3 \mathrm{H} ; \mathrm{CH}_{3}$ ). ESI-TOF-MS (positive) $\mathrm{m} / \mathrm{z}$ calcd for $\mathrm{C}_{22} \mathrm{H}_{23} \mathrm{ClF}_{3} \mathrm{~N}_{2} \mathrm{O}_{5}{ }^{+}[M+\mathrm{H}]^{+} 487.1242$, 489.1213; found $487.1168,489.1106$.<smiles>CCOc1ccc(NC(=O)CCCCC(=O)O)cc1C(=O)Nc1cc(C(F)(F)F)ccc1Cl</smiles><smiles>O=C(O)[C-][Nb]</smiles>

This compound was synthesized as $\mathrm{HO}_{2} \mathrm{C}-\mathrm{CTB} .{ }^{1} \mathrm{H}$ NMR $\left(600 \mathrm{MHz}, \mathrm{DMSO}-d_{6}\right): \delta=12.02(\mathrm{~s}, 1 \mathrm{H}), 10.60(\mathrm{~s}, 1 \mathrm{H})$, $10.00(\mathrm{~s}, 1 \mathrm{H}), 8.84(\mathrm{~s}, 1 \mathrm{H}), 8.27(\mathrm{~d}, J=1.0 \mathrm{~Hz}, 1 \mathrm{H}), 7.88(\mathrm{dd}, J=8.9,2.0 \mathrm{~Hz}, 1 \mathrm{H}), 7.83(\mathrm{~d}, J=8.2 \mathrm{~Hz}, 1 \mathrm{H}), 7.54(\mathrm{~d}$, $J=8.3 \mathrm{~Hz}, 1 \mathrm{H}), 7.27(\mathrm{~d}, J=9.6 \mathrm{~Hz}, 1 \mathrm{H}), 4.37(\mathrm{q}, J=7.1 \mathrm{~Hz}, 2 \mathrm{H}), 2.31(\mathrm{t}, J=7.2 \mathrm{~Hz}, 2 \mathrm{H}), 2.25(\mathrm{t}, J=7.5 \mathrm{~Hz}, 2 \mathrm{H})$, $1.61(\mathrm{~m}, 2 \mathrm{H}), 1.54(\mathrm{~m}, 2 \mathrm{H}), 1.45(\mathrm{t}, J=6.9 \mathrm{~Hz}, 3 \mathrm{H})$. ESI-TOF-MS (positive) $\mathrm{m} / \mathrm{z}$ calcd for $\mathrm{C}_{22} \mathrm{H}_{23} \mathrm{ClF}_{3} \mathrm{~N}_{2} \mathrm{O}_{5}{ }^{+}[M+\mathrm{H}]^{+}$ 487.1242, 489.1213; found 487.0917, 489.0889 .

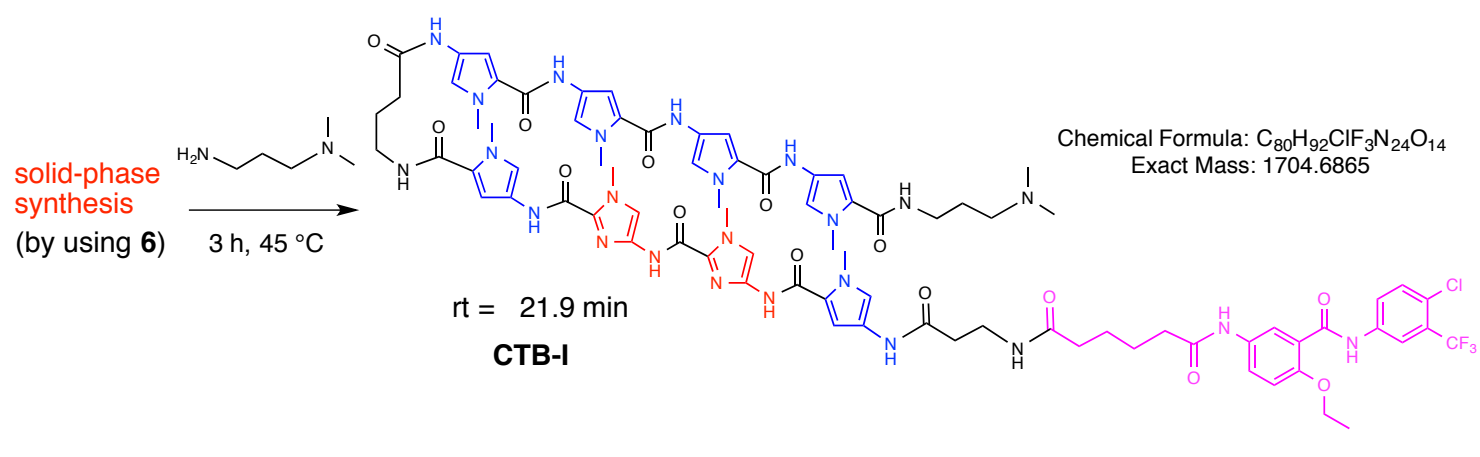

The preparation of P-I polyamide-CTB conjugates by Fmoc solid-phase synthesis. All machine-assisted polyamide syntheses were performed on a PSSM-8 peptide synthesizer (Shimadzu, Kyoto) with a computer-assisted operation system at $43 \mathrm{mg}$ of Fmoc-P-oxime resin (ca. $0.42 \mathrm{mmol} / \mathrm{g}, 100 \sim 200 \mathrm{mesh}$ ) by Fmoc solid-phase chemistry. Reaction cycles were as follows: deblocking steps for $4 \min \times 2,20 \%$ piperidine in DMF; coupling step for $60 \mathrm{~min}$, corresponding carboxylic acids, HCTU (88 mg), diisopropylethylamine (DIEA) (36 $\mu \mathrm{L})$, 1-methyl-2-pyrrolidone (NMP); washing steps for $1 \mathrm{~min} x$ 5, DMF. Each coupling reagents in steps were prepared in NMP solution of Fmoc-P-COOH (77 mg), Fmoc-I-COOH (77 mg), Fmoc-P-I-COOH (70 mg), Fmoc- $\beta$-COOH (66 mg), Fmoc- $\gamma$-COOH (69 mg) and HO $\mathbf{H}$-CTB 6 (103 mg). All other couplings were carried out with single-couple cycles with stirred by $\mathrm{N}_{2}$ gas bubbling. Typically, resin $(40 \mathrm{mg})$ was swollen in $1 \mathrm{~mL}$ of NMP in a $2.5-\mathrm{mL}$ plastic 
reaction vessel for $30 \mathrm{~min}$. 2-mL plastic centrifuge tubes with loading Fmoc-monomers with HCTU in NMP $1 \mathrm{~mL}$ were placed in programmed position. All lines were washed with NMP after solution transfers. After the completion of the synthesis by the peptide synthesizer, the resin was washed with DMF (1 mL x 2), methanol ( $1 \mathrm{~mL} \times 2)$, and dried in a desiccator at room temperature in vacuo.

CTB-ק-PIIP- $\boldsymbol{\gamma}$-PPPP-Dp (CTB-I). A dried sample resin was cleaved with $0.5 \mathrm{ml}$ of 3,3-dimethyaminopropylamine (Dp) for $3 \mathrm{~h}$ at $45^{\circ} \mathrm{C}$. The reaction mixture was filtered, triturated from $\mathrm{CH}_{2} \mathrm{Cl}_{2}-\mathrm{Et}_{2} \mathrm{O}$, to yield P-I polyamide as yellow crude powder $(38 \mathrm{mg})$. The crude was purified by flash column chromatography (elution with trifluoroacetic acid and a 0-45\% acetonitrile linear gradient (0-45 min) at a flow rate of $18 \mathrm{~mL} \mathrm{~min}^{-1}$ under $254 \mathrm{~nm})$ as white powder $(13 \mathrm{mg}) .{ }^{1} \mathrm{H}$ NMR $\left(600 \mathrm{MHz}\right.$, DMSO- $\left.d_{6}\right): \delta 10.50(\mathrm{~s}, 1 \mathrm{H}), 10.38(\mathrm{~s}, 1 \mathrm{H}), 10.25(\mathrm{~s}$, 1H), $9.93(\mathrm{~s}, 1 \mathrm{H}), 9.90(\mathrm{~s}, 4 \mathrm{H}), 9.84(\mathrm{~s}, 1 \mathrm{H}), 9.40(\mathrm{~s}, 1 \mathrm{H}), 8.32(\mathrm{~s}, 1 \mathrm{H}), 8.15(\mathrm{t}, J=6.2 \mathrm{~Hz}, 1 \mathrm{H}), 8.09(\mathrm{t}, J=5.5 \mathrm{~Hz}$ 1H), $7.95(\mathrm{~d}, J=7.6 \mathrm{~Hz}, 1 \mathrm{H}), 7.89(\mathrm{t}, J=5.5 \mathrm{~Hz}, 1 \mathrm{H}), 7.88(\mathrm{~d}, J=2.3 \mathrm{~Hz}, 1 \mathrm{H}), 7.72(\mathrm{dd}, J=8.9,2.0 \mathrm{~Hz}, 1 \mathrm{H}), 7.70$ $(\mathrm{d}, J=8.9 \mathrm{~Hz}, 1 \mathrm{H}), 7.63(\mathrm{~s}, 1 \mathrm{H}), 7.58(\mathrm{~s}, 1 \mathrm{H}), 7.29(\mathrm{~s}, 1 \mathrm{H}), 7.22(\mathrm{~s}, 2 \mathrm{H}), 7.20(\mathrm{~s}, 1 \mathrm{H}), 7.17(\mathrm{~s}, 2 \mathrm{H}), 7.11(\mathrm{~d}, J=8.8$ Hz, 1H), 7.07 (s, 2H), $7.04(\mathrm{~s}, 1 \mathrm{H}), 6.95(\mathrm{~s}, 1 \mathrm{H}), 6.93(\mathrm{~s}, 1 \mathrm{H}), 6.89(\mathrm{~s}, 1 \mathrm{H}), 4.11(\mathrm{q}, J=6.9 \mathrm{~Hz}, 2 \mathrm{H}), 4.011$ (s, 3H), $4.007(\mathrm{~s}, 3 \mathrm{H}), 3.850(\mathrm{~s}, 3 \mathrm{H}), 3.846(\mathrm{~s}, 3 \mathrm{H}), 3.83(\mathrm{~s}, 6 \mathrm{H}), 3.81(\mathrm{~s}, 6 \mathrm{H}), 3.31(\mathrm{~m}, 2 \mathrm{H}), 3.24(\mathrm{~m}, 4 \mathrm{H}), 3.07(\mathrm{~m}, 2 \mathrm{H}), 2.79$ (s, 3H), $2.78(\mathrm{~s}, 3 \mathrm{H}), 2.42(\mathrm{t}, J=6.9 \mathrm{~Hz}, 2 \mathrm{H}), 2.28(\mathrm{~m}, 4 \mathrm{H}), 2.08(\mathrm{t}, J=6.9 \mathrm{~Hz}, 2 \mathrm{H}), 1.84(\mathrm{~m}, 2 \mathrm{H}), 1.80(\mathrm{~m}, 2 \mathrm{H}), 1.54$ $(\mathrm{m}, 4 \mathrm{H}), 1.35(\mathrm{t}, J=6.9 \mathrm{~Hz}, 3 \mathrm{H})$ analytical HPLC $\mathrm{t}_{\mathrm{R}}=22.0 \mathrm{~min}$; ESI-TOF-MS m/z calcd for $\mathrm{C}_{80} \mathrm{H}_{94} \mathrm{ClF}_{3} \mathrm{~N}_{24} \mathrm{O}_{14}{ }^{2+}$ $[M+2 \mathrm{H}]^{2+} 853.3505$, found 853.3577 .

\section{CTB-Ne-p-PIIP- $\gamma$-PPPP-Dp (CTB-Ne-I.).}

Synthesis of the inactive CTB analogue conjugate (CTB-Ne-I) was carried out with the same scheme as CTB-I. analytical HPLC $t_{R}=15.3$ min (linear gradient of 0-100\% 0.1\% TFA/MeCN over $20 \mathrm{~min}$ ); ESI-TOF-MS m/z calcd for $\mathrm{C}_{80} \mathrm{H}_{94} \mathrm{ClF}_{3} \mathrm{~N}_{24} \mathrm{O}_{14}{ }^{2+}[M+2 \mathrm{H}]^{2+}$ 853.3505; found 853.3470. 
Analytical Data of $\mathrm{N}$-(4-chloro-3-(trifluoromethyl)phenyl)-2-ethoxybenzamide (CTB). Analytical HPLC $t_{\mathrm{R}}=31.8 \mathrm{~min}$; ESI-TOF-MS m/z calcd for $\mathrm{C}_{16} \mathrm{H}_{13} \mathrm{ClF}_{3} \mathrm{NO}_{2}{ }^{+}[M+\mathrm{H}]^{+}$344.0660, found 343.9595; purity: 95.3\%. ${ }^{1} \mathrm{H}$ NMR (600 MHz, $\left.\mathrm{CDCl}_{3}\right): \delta 10.30(\mathrm{~s}, 1 \mathrm{H}), 8.30-8.28(\mathrm{~m}, 1 \mathrm{H}), 7.99(\mathrm{~s}, 1 \mathrm{H}), 7.88(\mathrm{~s}, 1 \mathrm{H})$, 7.51-7.49 (m, 2H), 7.15-7.02 (m, 2H), $4.32(\mathrm{q}, J=6.9 \mathrm{~Hz}, 2 \mathrm{H}), 1.65(\mathrm{t}, J=6.9 \mathrm{~Hz}, 3 \mathrm{H})$.

\section{Cell culture and optimization of parameters for treatment of CTB-PIP}

HDF from 54-year-old Caucasian female were purchased from Cell Applications, Inc. We used these cells for the screening studies and maintained in Dulbecco's modified eagle medium (DMEM, Nacalai Tesque, Japan) containing $10 \%$ fetal bovine serum (FBS, Japan Serum) and $0.5 \%$ as mentioned before. ${ }^{2}$ HDF cells of P6 were trypsinized for $5 \mathrm{~min}$ at $37^{\circ} \mathrm{C}$, and were treated by the addition of $1 \mathrm{mM}$ of each individual effectors (CTB, CTB-I, SAHA-I and SAHA) to achieve a final polyamide concentration of $1 \mu \mathrm{M}$ in $0.5 \% \mathrm{DMSO}$ and then were incubated in a $5 \% \mathrm{CO}_{2}$ atmosphere at $37{ }^{\circ} \mathrm{C}$ for $48 \mathrm{~h}$ as mentioned before. ${ }^{3} 0.5 \%$ DMSO treated cells were used as the control. Effective concentration of the CTB-PIPs was standardized based on the initial optimization experiments and the treatment of HDF with various concentration of PI polyamide CTB conjugates $(500 \mathrm{nM}, 1 \mu \mathrm{M}, 5 \mu \mathrm{M}$ and $10 \mu \mathrm{M})$. After $1 \mu \mathrm{M}$, no significant effect on the induction pattern was observed by increasing the concentration. Optimization studies for incubation time ( $24 \mathrm{~h}, 48 \mathrm{~h}$ and $72 \mathrm{~h}$ ) suggested again that $48 \mathrm{~h}$ is optimal.

\section{Microarray analysis and Quantification of gene expression}

HDFs were treated with $1 \mu \mathrm{M}$ of effectors and after $48 \mathrm{~h}$ incubation total RNA was isolated using RNeasy MINI Kit (Qiagen, CA, USA) according to the manufacturer's instructions. Microarray studies were then carried out as mentioned before ${ }^{3}$ using Human Gene 2.1 ST Array (Affymetrix, USA). The raw data and associated sample information were processed by Expression Console (Affymetrix, USA) and Transcriptome Analysis Console (Affymetrix, USA). The interpretation of the microarray data is carried out by Ingenuity pathway analysis as mentioned before ${ }^{2,3}$. Unsupervised clustering analysis was performed using Cluster 3.0 and the results were 
visualized using Java Treeview as mentioned before ${ }^{3}$. Fischer's exact test were employed to measure the p-value that determines the association between the genes in the dataset and the library of canonical pathways in the Ingenuity pathway knowledge base. For scatter plot analysis, transcripts upregulated in CTB-I-treated HDFs ( $>2$ fold, p $<0.05$ in comparison with DMSO-treated HDFs) were extracted and plotted against the data obtained in SAHA-I treated HDFs.

Quantification of gene expression was carried using a ReverTra Ace qPCR RT kit (Toyobo, Japan) and real-time RT-PCR amplifications were carried out in triplicate with THUNDERBIRD SYBR qPCR Mix (TOYOBO, Japan) and analyzed by using ABI 7300 Real-Time PCR System (Applied Biosystems, USA) as mentioned before ${ }^{1-3}$. The relative expression level was calculated using DMSO treated cells as the internal control (1-fold) after normalization with GAPDH. Primer pairs used for RT-PCR analysis were as shown before ${ }^{3}$. The statistical significance was determined by the $t$ test.

\section{Chromatin immunoprecipitation sequencing (ChIP-Seq) analysis}

ChIP-PCR was done after immunoprecipitating HDFs treated with CTB-I for $48 \mathrm{~h}$, and the amount of promoter sequence of OCT-3/4 in the co-precipitated DNA was measured as before ${ }^{3}$. ChIP-Seq experiments with an H3K14ac-specific antibody were conducted to gain better understanding of CTB-I- mediated acetylation under the conditions mentioned before and as follows ${ }^{3}$. ChIP-Seq libraries were prepared with standard Ion Xpress ${ }^{\mathrm{TM}}$ Plus gDNA Fragment Library Preparation reagents and protocols (Life Technologies, USA) and checked with Agilent DNA High sensitivity BioAnalyzer kit (Agilent Technologies, USA). Template preparation with the qualified libraries was done using Ion PGMTM template OT2 200 kit and Ion PITM template OT2 200 kit in Ion one touch2 system. The templates were then enriched in Ion one touch ES and sequenced with Ion PGM sequencer using Ion PGMTM sequencing 200 kit v2 / 318 chip and Ion ProtonTM Sequencer using Ion PITM Sequencing 200 kit / Ion PI chip by following the manufacturer's instructions. The data were processed by employing standard program packages 
in the Ion torrent suit. Torrent Mapping Alignment Program 3.4.3-1 (TMAP) was used for aligning reads, ChIP-seq peaks was called using MACS $1.4 .2^{4}$

\section{Cytotoxicity assay}

Colorimetric assays were done as mentioned previously using WST-8 (Dojindo, Kumamoto, Japan) in 96-well plates with various concentrations of CTB and CTB-I as mentioned before ${ }^{3}$.

\section{Histone acetyl transferase (HAT) activity assay}

HAT assay was performed to quantify the HAT activity using HAT Activity Fluorometric Assay Kit (BioVision K334-100). Nuclear extracts were collected and purified using Nuclear/Cytosol Fractionation Kit (BioVision K266-100). Experiments were carried out using both kits according to the manufacturer's protocol.

\section{Histone deacetylase (HDAC) activity assay}

To quantify the HDAC activity, Calorimetric assay was performed using Color de Lys ${ }^{\mathrm{TM}}$ kit (BML-AK500) according to manufacturers instructions. HDF nuclear extracts were collected using Nuclear/Cytosol Fractionation Kit (BioVision K266-100). HeLa nuclear extracts supplied by the manufacturer was used as control. 
Fig. S1

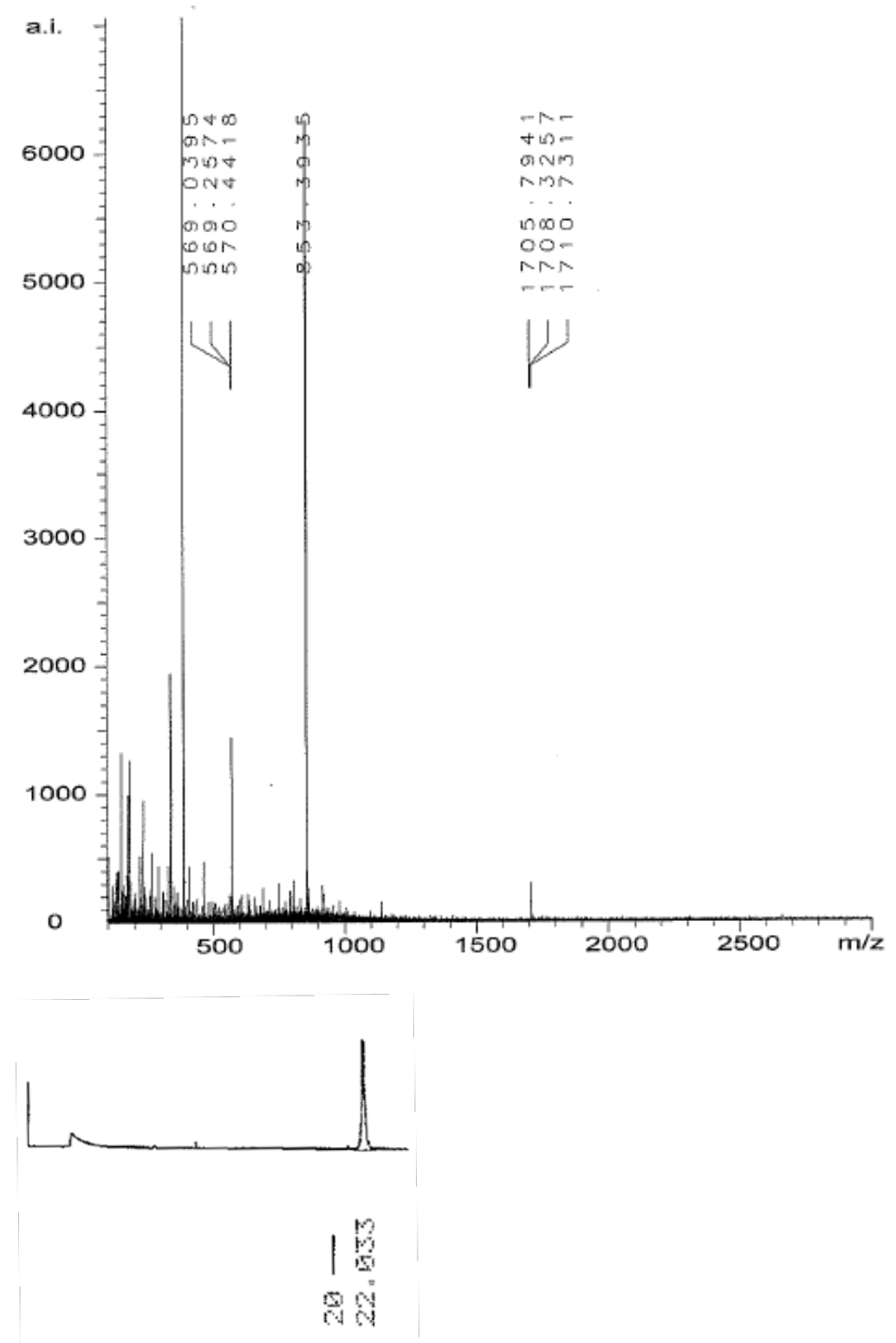

Retention time: $20.03 \mathrm{~min}$

Figure S1. Mass spectrum and HPLC chromatogram of CTB-I. The purities of the CTB-PIP-I were checked by HPLC (elution with $0.1 \%$ aqueous solution of trifluoroacetic acid and a linear gradient of $0-100 \%$ acetonitrile over 40 min at a flow rate of $1.0 \mathrm{~mL} \mathrm{~min}^{-1}$ under $254 \mathrm{~nm}$ ). 
Fig. S2.

a.

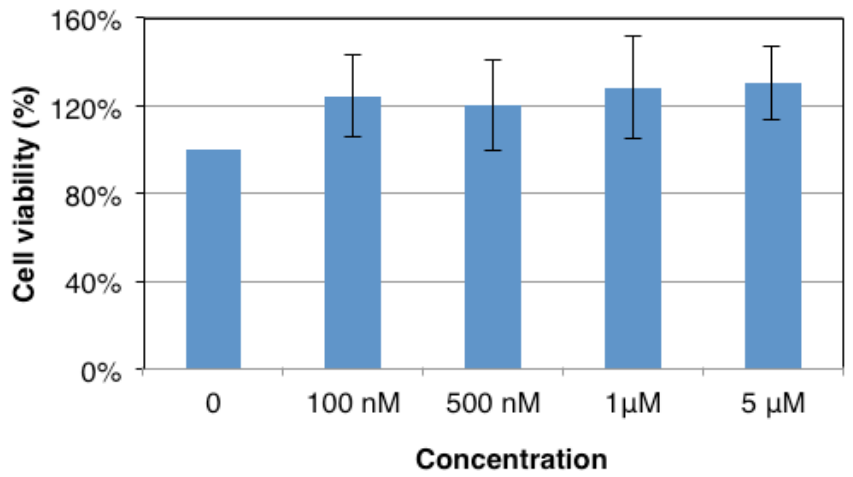

b.

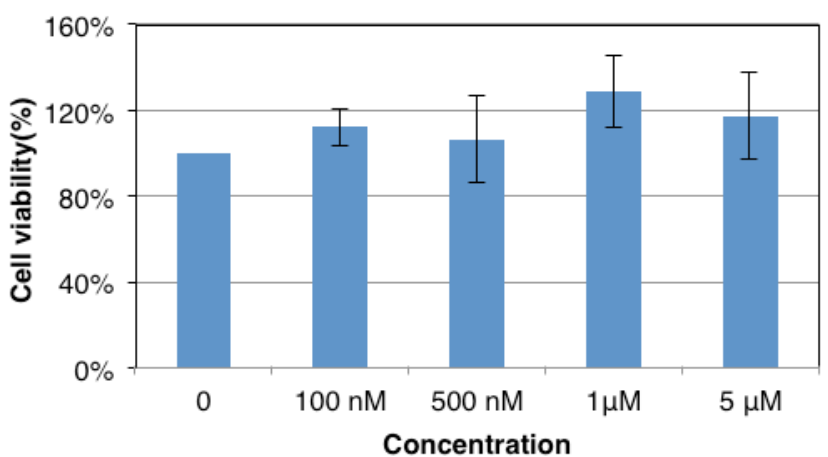

Figure S2. Cytotoxicity assay of (a) CTB and (b) CTB-PIP-I or CTB-I. Cell viability of HDF was measured after 48 $\mathrm{h}$ treatment of the above effectors with various concentrations. Each bar represents mean \pm SD from 12 wells. 
Fig. S3.

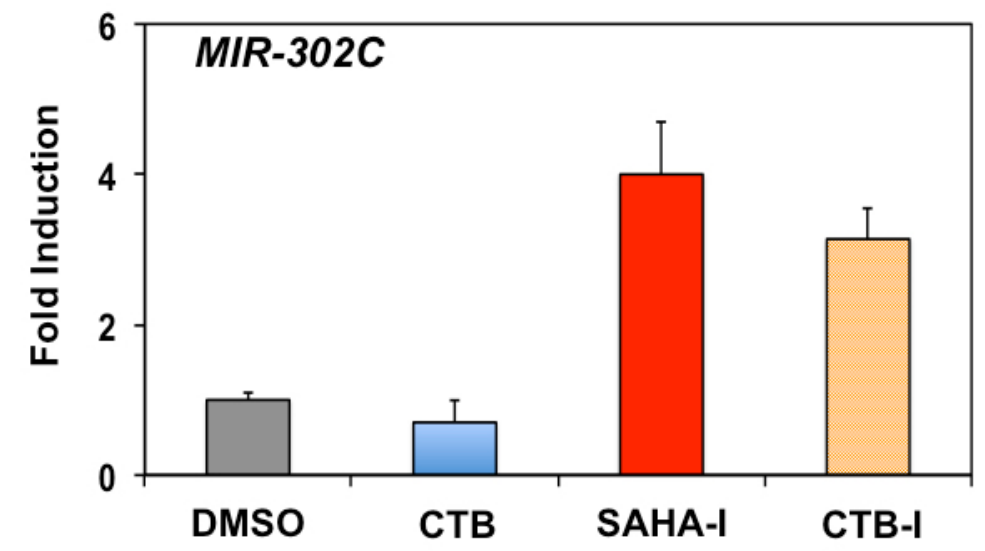

Figure S3. Q-RT-PCR analysis of $M I R-302 C$ in the effectors (CTB, CTB-I and SAHA-I) treated HDFs at a concentration of $1 \mu \mathrm{M}$. Cells treated with $0.5 \%$ DMSO were used as the internal standard. Each bar represents the mean \pm SD from 18 wells (6 biological replicates). 
Fig. S4.

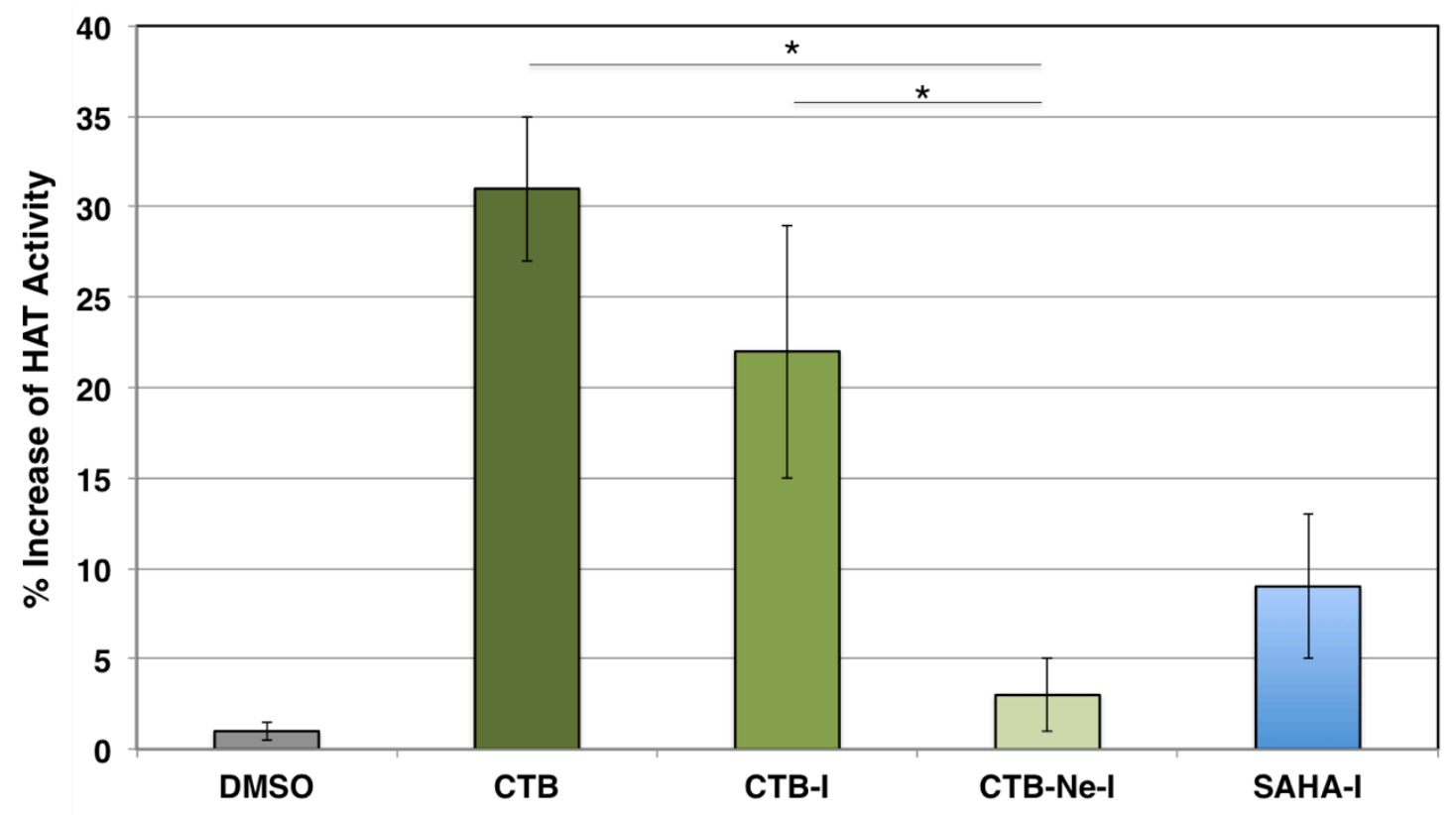

Figure S4. The HAT activity in HDFs individually treated with $1 \mu \mathrm{M}$ of CTB, CTB-I, CTB-Ne-I and SAHA-I for 48 h. Nuclear/Cytosol Fractionation Kit (BioVision K266-100) is used to collect and purify the nuclear extract. The increase of HAT activity for all samples was determined using HAT Activity Fluorometric Assay Kit (BioVision K334-100) after normalizing the values to the untreated HDF cells. 0.5\% DMSO-treated cells were used as the control. The standard error is derived from three independent wells. ${ }^{*} \mathrm{p}<0.05$ vs. CTB-Ne-I. 
Fig. S5.

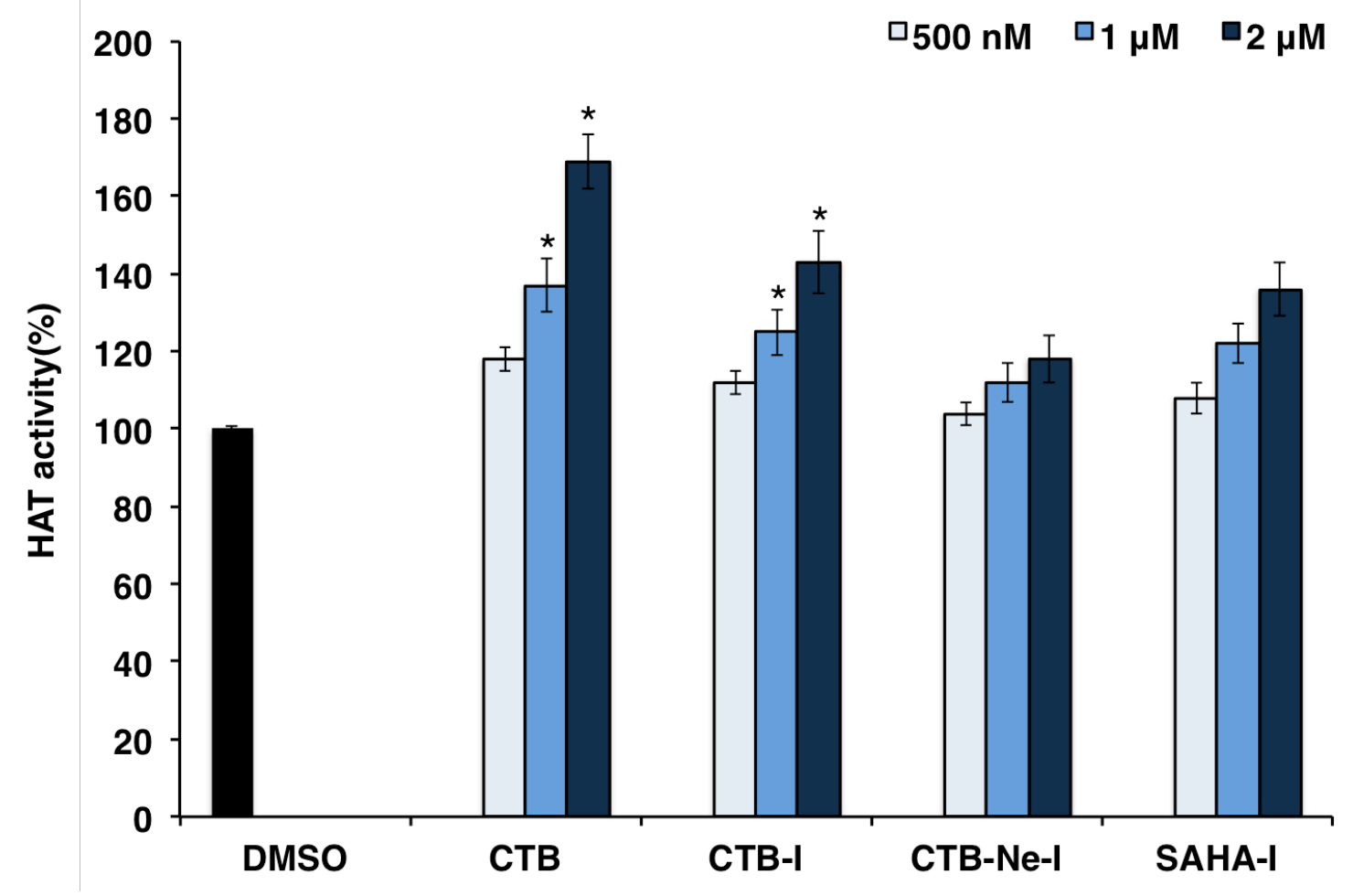

Figure S5. Enzymatic activity of HAT was tested in the presence of CTB, CTB-I, CTB-Ne-I and SAHA-I for 60 min.

Each effector was individually treated at three different concentration (500 nM, $1 \mu \mathrm{M}$ and $2 \mu \mathrm{M})$ to HeLa cell nuclear extract and the increase in activity is shown by comparing the activity of the extract in the presence of $0.5 \%$ DMSO $(100 \%) ; \quad{ }^{*} \mathrm{p}<0.05$ 
Fig. S6.

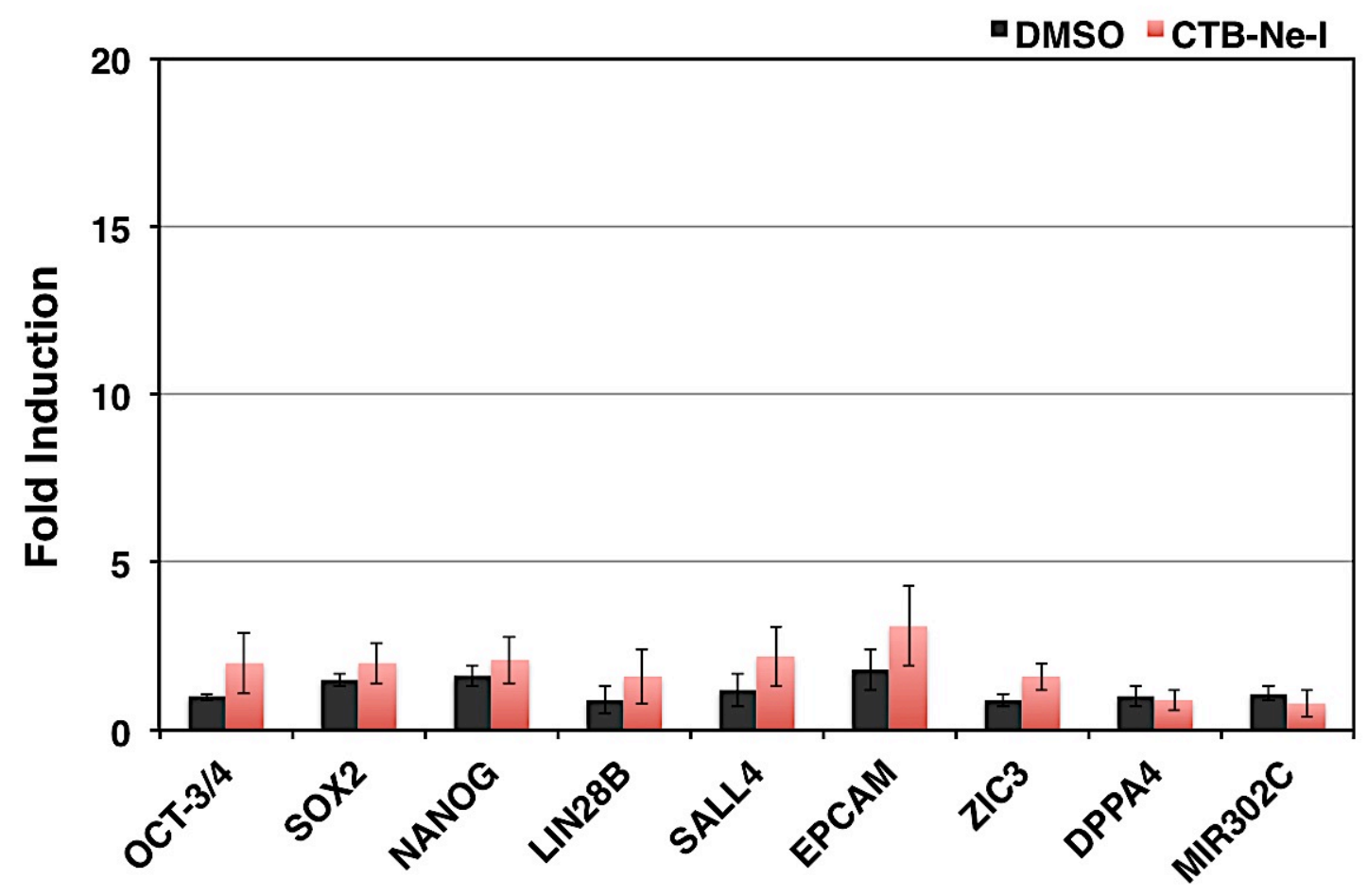

Figure S6. Q-RT-PCR analysis of OCT-3/4, SOX2, NANOG, LIN28B. SALL4, EPCAM, ZIC3, DPPA4 and MIR302C in HDFs treated with CTB-Ne-I at a concentration of $1 \mu \mathrm{M}$. Cells treated with $0.5 \%$ DMSO were used as the internal standard. Each bar represents the mean \pm SD from 6 wells. 
Fig. S7.

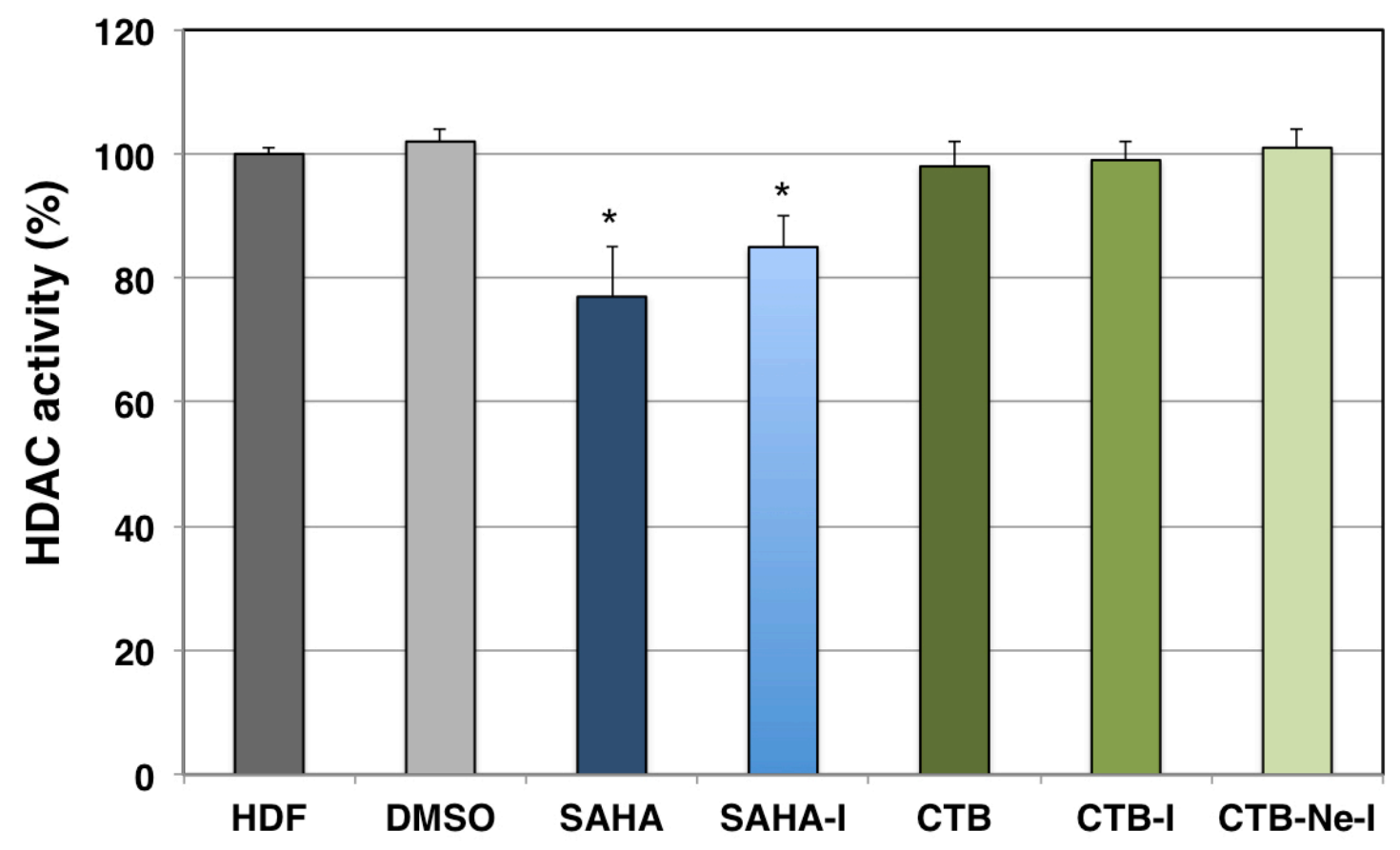

Figure S7. HDAC activity in HDFs individually treated with $1 \mu \mathrm{M}$ of CTB, CTB-I, CTB-Ne-I and SAHA-I for $48 \mathrm{~h}$ was analyzed using Color de Lys ${ }^{\mathrm{TM}}$ kit (BML-AK500). Nuclear extracts collected as shown in Figure S4 was incubated $\left(37^{\circ} \mathrm{C}\right)$ with $0.2 \mathrm{mM}$ substrate. Reactions were stopped after $30 \mathrm{~min}$. with Color de Lys ${ }^{\mathrm{TM}}$ Developer and the absorbance measured at $405 \mathrm{~nm} .{ }^{*} \mathrm{p}<0.05 \mathrm{Vs}$ HDF. 
Fig. S8.

a.
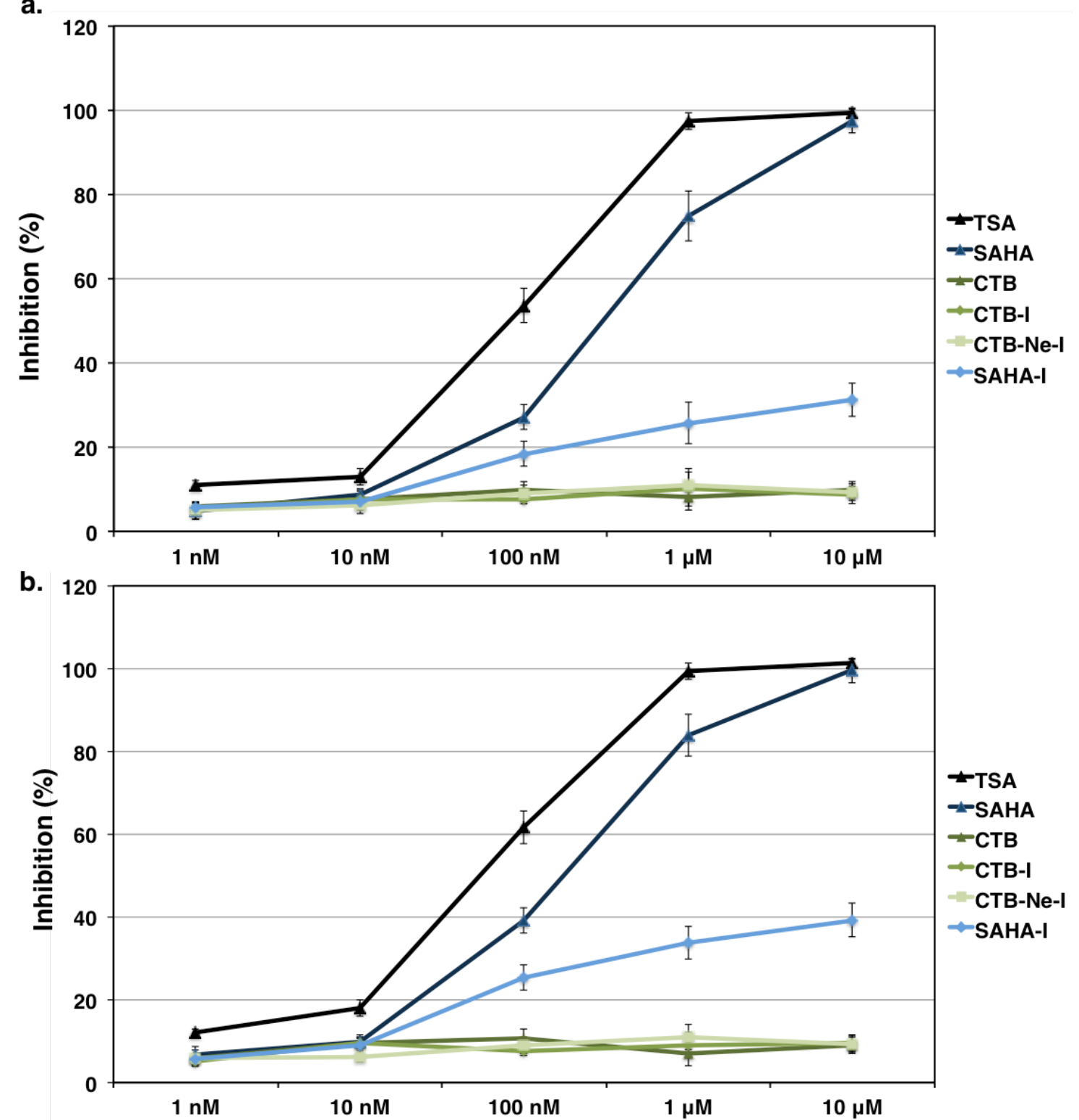

Figure S8. Inhibition of Color de Lys ${ }^{\mathrm{TM}}$ Substrate Deacetylation by (a) HeLa Nuclear Extract and (b) HDF nuclear extract within Trichostatin A (Black), SAHA (Dark blue), SAHA-I (Light blue), CTB (Dark green), CTB-I (Medium green) and CTB-Ne-I (Light green), respectively. Nuclear Extract was incubated as in Figure S7 with indicated concentrations of the effectors. Reaction was stopped after $30 \mathrm{~min}$. with Color de Lys ${ }^{\mathrm{TM}}$ Developer and the absorbance measured at $405 \mathrm{~nm}$. 
Fig. S9

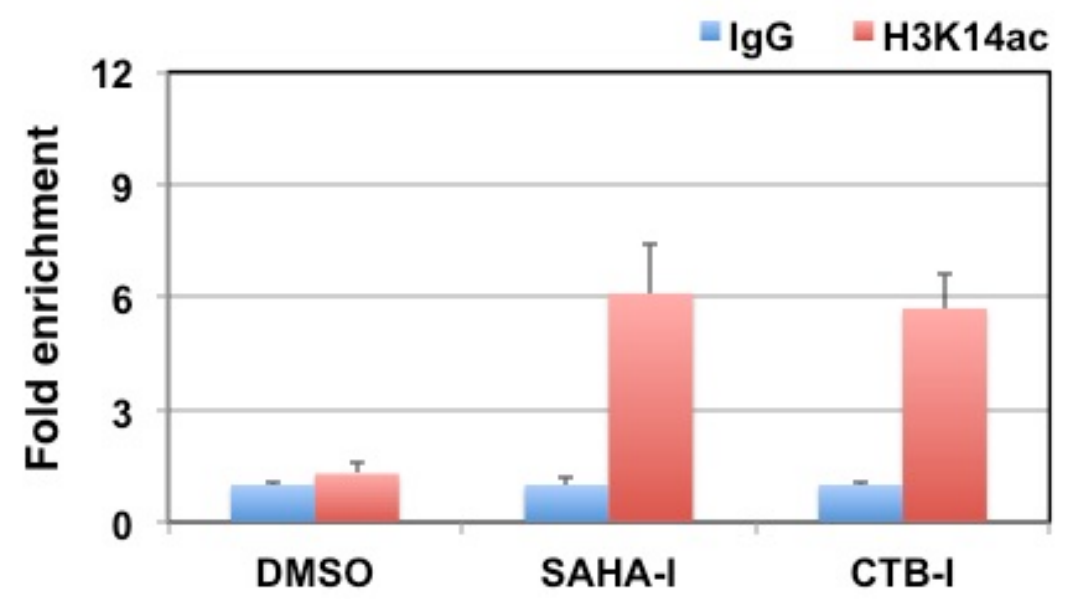

Figure S9. Chromatin immunoprecipitation analysis was carried out ${ }^{3}$ after immunoprecipitation with H3K14Ac antibody and the amount of promoter sequence of $O C T-3 / 4$ in the co-precipitated DNA was determined by qPCR. Each bar represents the mean \pm SD from 3 wells. 
Fig. S10

a.

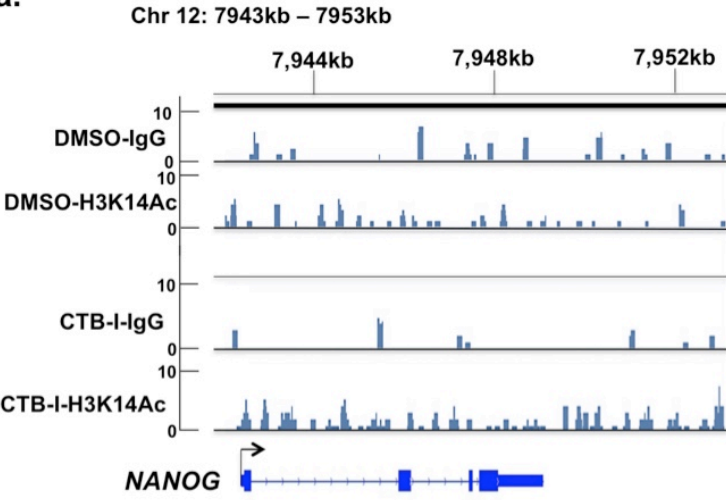

c.

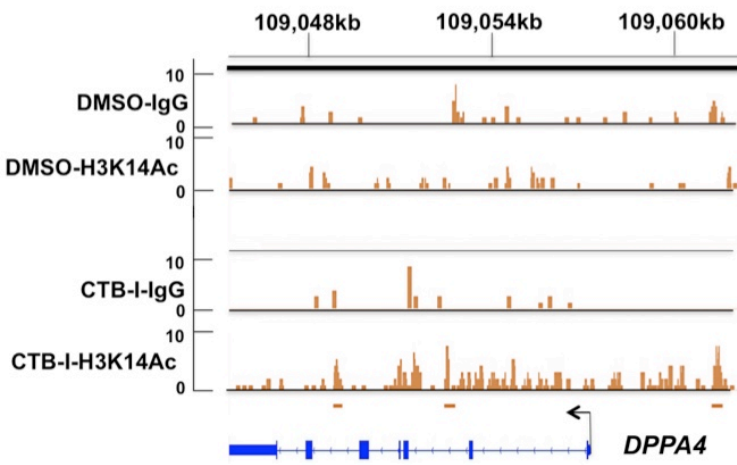

e.

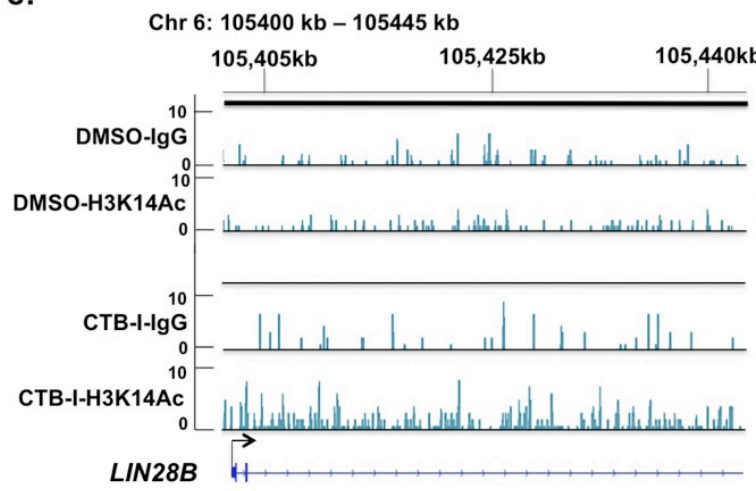

Chr 3: $181426 \mathrm{~kb}-181440 \mathrm{~kb}$

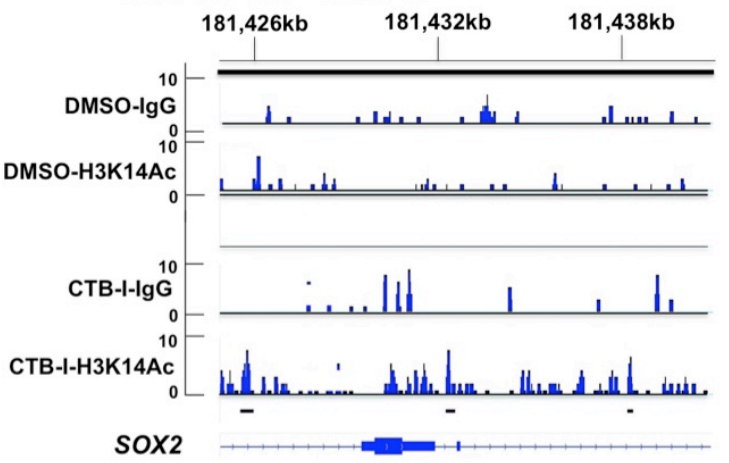

d. Chr 2: $47590 \mathrm{~kb}-47610 \mathrm{~kb}$

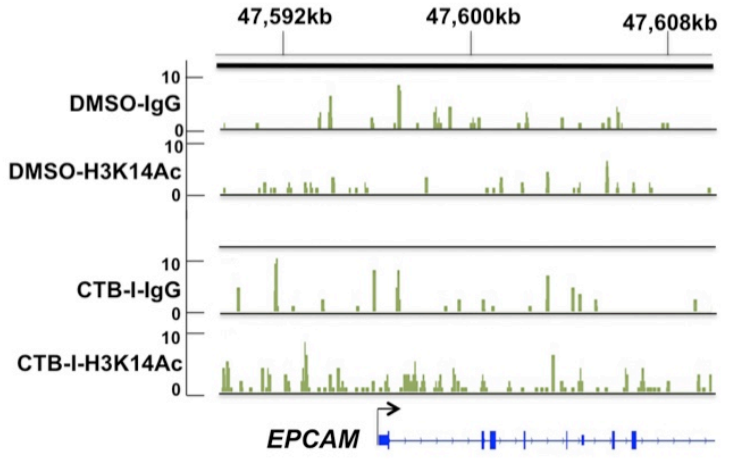

f.

Chr X: $136638 \mathrm{~kb}-1136649$

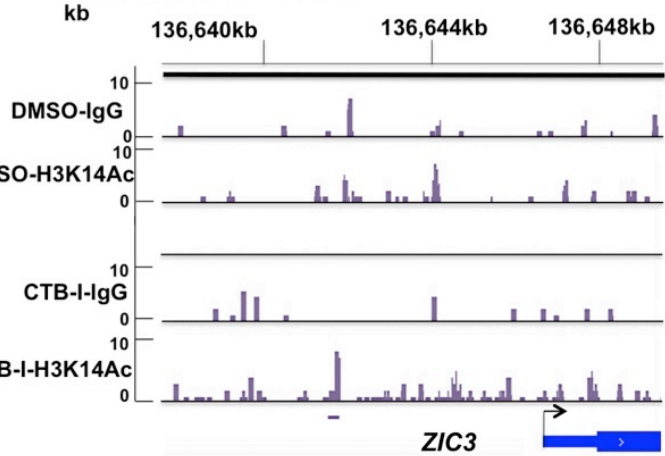

Figure S10. ChIP-Seq analysis of the $O C T-3 / 4$ regulated pluripotency gene (a) $N A N O G$, (b) $S O X 2$, (c) DPPA4, (d)

EPCAM, (e) LIN28B and (f) ZIC3 regions was performed with H3K14Ac antibody as mentioned before ${ }^{3}$. 
Fig. S11

a.

Chr 12: $130800 \mathrm{~kb}-130840 \mathrm{~kb}$

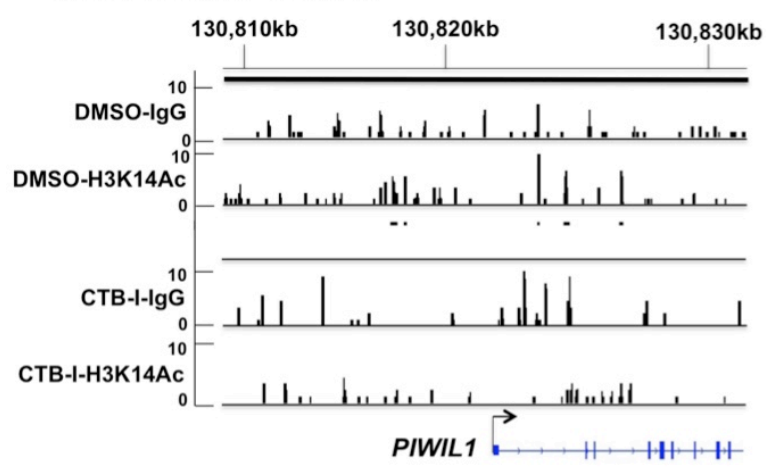

c.

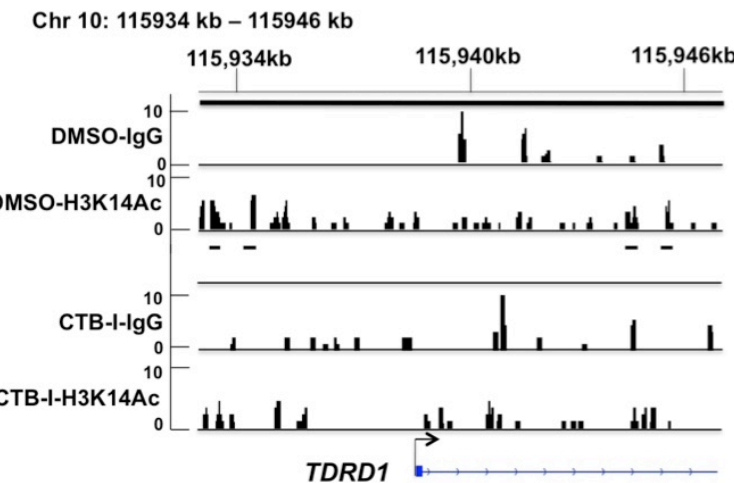

b.

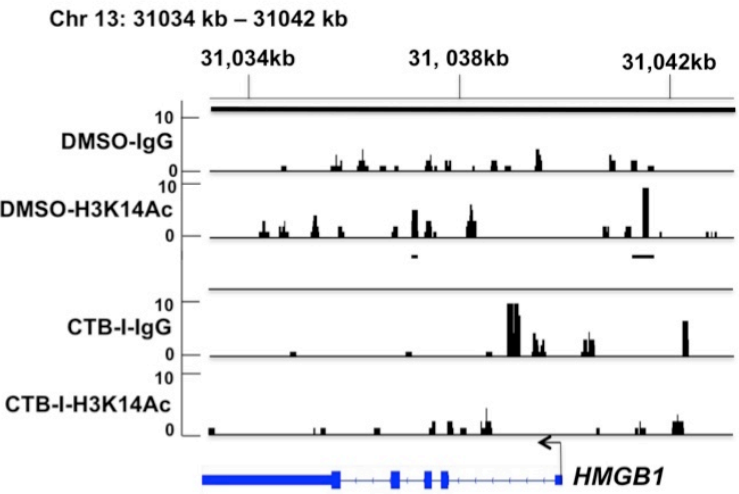

d.

Chr 12: $6638 \mathrm{~kb}-6644 \mathrm{~kb}$

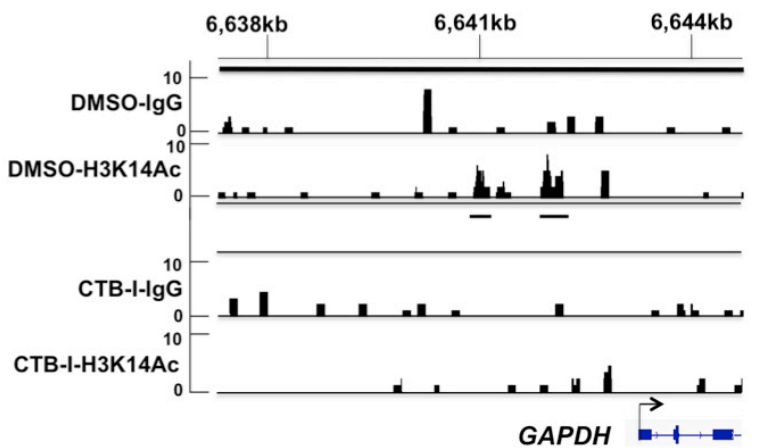

Figure S11. ChIP-Seq analysis of the control genes (a) PIWIL1, (b) HMGB1, (c) TDRD1, and (d) GAPDH was performed with H3K14Ac antibody as mentioned before ${ }^{3}$. 
Fig. S12.

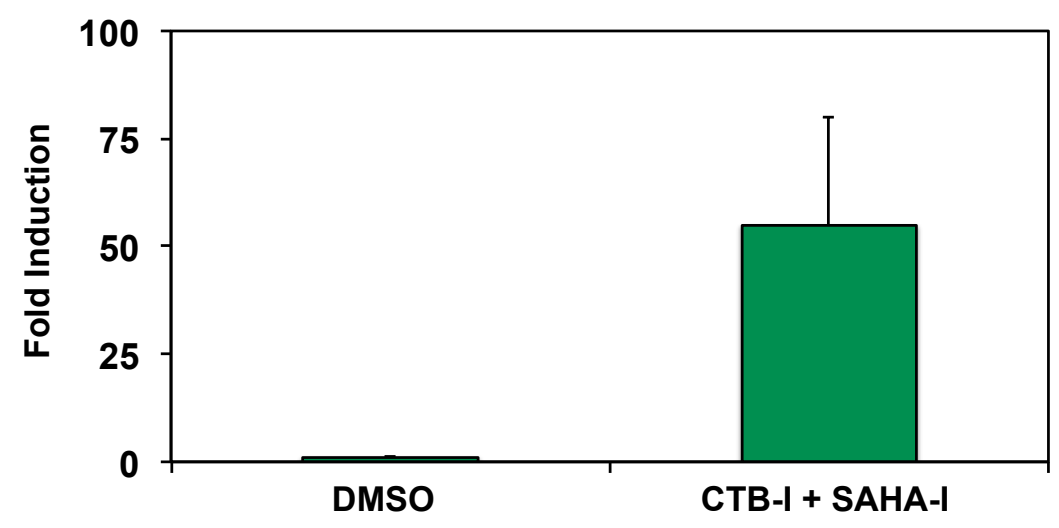

Figure S12. Q-RT-PCR analysis of $O C T-3 / 4$ in HDFs treated with the combination of CTB-I and SAHA-I at a final concentration of $1 \mu \mathrm{M}$. Cells treated with $0.5 \%$ DMSO were used as the internal standard. Each bar represents the mean \pm SD from 18 wells (6 biological replicates). 
Table S1. Effector modulated genes in human dermal fibroblasts

\begin{tabular}{lll}
\hline Effectors & Up regulated & Down regulated \\
& Genes $^{\text {a }}$ & Genes $^{\text {a }}$ \\
\hline SAHA-I & 74 & 13 \\
CTB-I & 48 & 19 \\
CTB & 53 & 45 \\
\hline
\end{tabular}

${ }^{\mathrm{a}}$ Expression data derived from four wells 
Table S2. Differentially expressed genes in top five pathways in

\begin{tabular}{|c|c|c|}
\hline \multicolumn{3}{|l|}{ CTB-I treated HDFs } \\
\hline Pathway & $-\log (p \text {-value })^{a}$ & Genes \\
\hline $\begin{array}{l}\text { Role of Oct } 4 \text { in Mammalian Embryonic } \\
\text { Stem Cell Pluripotency }\end{array}$ & 4.07 & $\begin{array}{l}\text { NANOG, SOX2, NR6A1, IGF2BP1, SALL4, } \\
\text { POU5F1 }\end{array}$ \\
\hline $\begin{array}{l}\text { Transcriptional Regulatory Network in } \\
\text { Embryonic Stem Cells }\end{array}$ & 3.34 & ZIC3, POU5F1, NANOG, SOX2, RFX4 \\
\hline $\begin{array}{l}\text { Embryonic Stem Cell Differentiation } \\
\text { into Cardiac Lineages }\end{array}$ & 3.33 & NANOG, SOX2, POU5F1 \\
\hline $\begin{array}{l}\text { Human Embryonic Stem Cell } \\
\text { Pluripotency }\end{array}$ & 2.18 & $\begin{array}{l}\text { SOX2, NANOG, FZD3, FGFR2, SALL4, POU5F1, } \\
\text { ZIC3 }\end{array}$ \\
\hline $\begin{array}{l}\text { Autoimmune Thyroid Disease } \\
\text { Signaling }\end{array}$ & 2.15 & $\begin{array}{l}\text { HLA-DQB1, IGHG1, HLA-DQA1, CD40LG, HLA- } \\
\text { DOA, HLA-DRA, IL2 }\end{array}$ \\
\hline \multicolumn{3}{|l|}{ CTB treated HDFs } \\
\hline Pathway & $-\log (\mathrm{p}$-value $)$ & Genes \\
\hline LXR/RXR Activation & 2.46 & $\begin{array}{l}\text { LYZ, TF, MMP9, SAA4, IL1RAPL2, APOC1, } \\
\text { IL1RAPL1, IL36G, AMBP, IL1F10 }\end{array}$ \\
\hline Nicotine Degradation III & 2.35 & $\begin{array}{l}\text { UGT2B4, UGT2B17, CYP3A4, UGT2A1, CYP3A7, } \\
\text { CYP1B1 }\end{array}$ \\
\hline Melatonin Degradation I & 2.23 & $\begin{array}{l}\text { UGT2B4, UGT2B17, CYP3A4, UGT2A1, CYP3A7, } \\
\text { CYP1B1 }\end{array}$ \\
\hline $\begin{array}{l}\text { Superpathway of Melatonin } \\
\text { Degradation }\end{array}$ & 2.05 & $\begin{array}{l}\text { UGT2B4, UGT2B17, CYP3A4, UGT2A1, CYP3A7, } \\
\text { CYP1B1 }\end{array}$ \\
\hline Nicotine Degradation II & 2.02 & $\begin{array}{l}\text { UGT2B4, UGT2B17, CYP3A4, UGT2A1, CYP3A7, } \\
\text { CYP1B1 }\end{array}$ \\
\hline
\end{tabular}

${ }^{a}$ Fischer's exact test from data obtained from 4 wells. 


\section{References}

[1] K. Mantelingu, A. H. Kishore, K. Balasubramanyam, G. V. P. Kumar, M. Altaf, S. N. Swamy, R. Selvi, C. Das, C. Narayana, K. S. Rangappa, T. K. Kundu, J. Phys. Chem. B 2007, 111, 4527-4534

[2] a) L. Han, G. N. Pandian, S. Junetha, S. Sato, C. Anandhakumar, J. Taniguchi, A. Saha, T. Bando, H. Nagase, H. Sugiyama, Angew. Chem. Int. Ed. 2013, 52, 13410-13413; b) G. N. Pandian, J. Taniguchi, S. Junetha, S. Sato, L. Han, A. Saha, C. AnandhaKumar, T. Bando, H. Nagase, T. Vaijayanthi, R. D. Taylor, H. Sugiyama, Sci. Rep. 2014, 4, e3843.

[3] G. N. Pandian, S. Sato, C. Anandhakumar, J. Taniguchi, K. Takashima, J. Syed, L. Han, A. Saha, T. Bando, H. Nagase, H. Sugiyama, ACS Chem. Biol. 2014, 9, 2729-2736.

[4] J. Feng, T. Liu, B. Qin, Y. Zhang, X. S. Liu, Nat. Protoc. 2012, 7, 1728-1740.

[5] K. Balasubramanyam, V. Swaminathan, A. Ranganathan, T. K. Kundu, J. Biol. Chem. 2003, 278, 19134-19140. 